For The Linguistics Companion, Blackwell. Final, pre-publication version, August 2002

\title{
N-words and Negative Concord
}

Anastasia Giannakidou

University of Chicago

\section{Table of Contents}

\section{$1 \quad$ Introduction}

2 The interpretation of negative concord and the nature of n-words

2.1 Negative absorption

2.2 N-words as indefinites

2.3 N-words and universal quantifiers

2.3.1. Universal quantifiers and $\mathrm{n}$-words: parallelism in scope

2.3.2 Negative concord as a universal scoping above negation

2.3.3 Commitment of existence

2.3.4 Existence, familiarity, and topicalization

2.3.5 Summary

3 Two basic varieties of negative concord and the distribution of $n$-words

3.1 Strict and non-strict varieties of negative concord

3.2. The position of n-words: preverbal versus postverbal

3.3 A typology of n-words

4 The issue of negativity

4.1 Negative meaning and ellipsis

4. 2 Nonnegative readings of $n$-words

5 The possibility of having an existential polarity item under negation

5.1 Negative concord versus existential dependencies: locality

5.1.1 N-words in islands

5.1.2 N-words in embedded clauses

5.1.3 Preceding negation

5.2 Existential polarity items and the semantics of n-words

5.2.1 Almost/absolutely modification

5.2.2 ke-' and' modification

5.2.3 Donkey anaphora

5.2.4 Use in predicate nominals

5. 3 Summary

\section{Concluding remarks}

Notes

References 


\section{$1 \quad$ Introduction}

In this paper we discuss the semantic and syntactic properties of a set of expressions known as $n$-words. The term is coined in Laka (1990) and is employed to refer to nominal and adverbial constituents that appear in negative concord (NC) structures. Although the term has been quite popular, curiously, it has never been defined in the strict semantic or syntactic sense. N-words crosslinguistically form a quite heterogeneous class in terms of both their distribution and semantic properties, hence the task of assigning a clear semantic or syntactic criterion for what constitutes an n-word becomes rather tricky. Fortunately, there are some distributional criteria that single out $n$-words from other negation-related elements. We use these in the working definition we adopt in this paper:

\section{$N$-word}

An expression $\alpha$ is an n-word iff:

(a) $\alpha$ can be used in structures containing sentential negation or another $\alpha$-expression yielding a reading equivalent to one logical negation; and

(b) $\alpha$ can provide a negative fragment answer.

This definition is general enough to capture the (quite diverse) data that we will present in section 3; at the same time, it can serve as the basis for distinguishing between 'weaker' and 'stronger' n-words; e.g. we can derive a class of 'stronger' n-words by substituting the modal can in (1a) with must. $\mathrm{N}$-words in languages that exhibit strict $\mathrm{NC}$, requiring that the sentential negative marker (SN) be always present in the structure containing the n-word, are stronger in this sense (the relevant data will be presented in section 3 ).

On the other hand, negative quantifiers in Germanic languages, which do not exemplify $\mathrm{NC}$, do not fall under (1) ${ }^{1}$; nor do existential polarity items (PIs) that are licensed by negation, as well as other noveridical licensers, e.g. English any, or Serbian/Croatian $i$-NPIs (the terminology from Progovac 1988, 1994)-since these PIs do not satisfy (1b) and cannot provide negative fragment answers. Why this is so is not pertinent to our discussion, but see Giannakidou (2000: 469, fn. 6) for an explanation. Note that we refer to these items as polarity items and not 'negative' polarity items (NPIs) because, as we said, they are licensed in a (large) variety of contexts that are not negative but nonveridical (in the sense of Giannakidou 1998, 1999). The term NPI will be used to only refer to PIs that are licensed by negation (or, more generally, antiveridicality). N-words in strict NC are in fact prototypical NPIs because they are not licensed by operators other than negation and anitveridical without.

$\mathrm{NC}$ is a phenomenon known to linguistics since Jespersen's (1917) double attraction, Klima's (1964) neg-incorporation, and Labov's (1972) negative attraction rule. Roughly, we talk about 'negative concord' in situations where negation is interpreted just once although it seems to be expressed more than once in the clause. One occurrence of negation is the $\mathrm{SN}$, and given that n-words can provide negative answers in isolation, as we see in (3), we can speculate that the additional occurrence of negation is the n-word. Here are some examples:

$$
\begin{array}{ll}
\text { a. Gianni *(non) ha visto niente. } \\
\text { John not have.3sg seen n-thing } \\
\text { 'John didn't see anything.' } \\
\text { *(No) he dit res. } \\
\text { not have.1sg said n-thing } \\
\text { 'I didn't say anything. ' } \\
\text { Balázs *(nem) látott semmit. } \\
\text { Balázs not saw.3sg n-thing } \\
\text { 'Balázs didn't see anything. ' } \\
\text { Milan *(ne) vidi nista. } \\
\text { Milan not see.3sg n-thing } \\
\text { 'Milan cannot see anything. ' }
\end{array}
$$

Italian

Catalan

Hungarian

Serbian/Croatian 


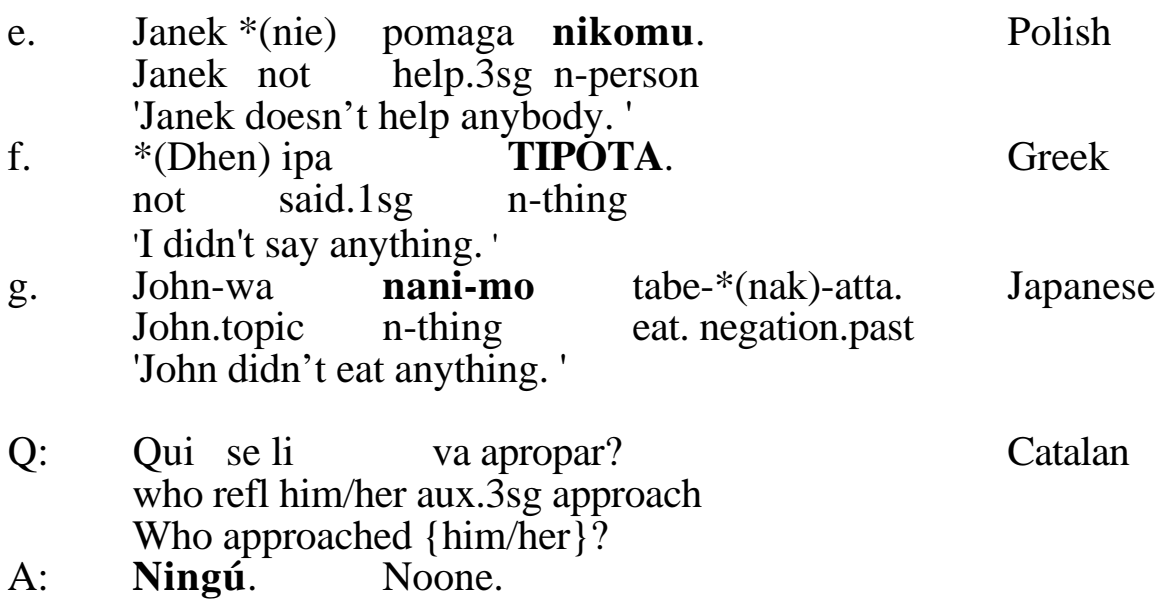

NC is observed in many languages; e.g. Romance, Slavic, Greek, Hungarian, Nonstandard English, West Flemish, Afrikaans, Lithuanian, Japanese (see among others Labov 1972, Ladusaw 1992, 1994, van der Wouden and Zwarts 1993; Bosque 1980, Laka 1990, Herburger 2001 for Spanish, Zanuttini 1991, Longobardi 1991, Acquaviva 1993, 1995, 1997 and Tovena 1996 for Italian, Quer 1993, 1994, Vallduvi 1994 for Catalan, Puskás 1998, Tóth 1999, Suranyi 2002 for Hungarian, Giannakidou 1997, 1998, 2000 for Greek, Haegeman 1995 and den Besten 1986 for West Flemish and Afrikaans, Hoeksema 1997 for Middle Dutch, Progovac 1988, 1994 for Serbian/Croatian, Brown 1999 for Russian, Przepiórkowski and Kupc 1997, 1998, Blaszczak 1999, and Richter and Sailer 1998 for Polish; Watanabe to appear for Japanese). These are the languages we consider here, though our primary focus will be on the three large European families - Greek, Romance, Slavic - , and Hungarian.

The sentences in (2) exemplify the variety known as negative concord proper: they contain sentential negative markers, which contribute logical negation $\neg$, and the n-words. ${ }^{2}$ Uppercase letters in the Greek n-word in (2f) indicate that it is pronounced emphatically; henceforth we will refer to Greek n-words as 'emphatics'. This accent is not related to focus for reasons that have been discussed in Giannakidou (1997, 1998: 227-231); see, however, Tsimpli and Roussou 1996 for a focus-based account). Emphatic accent is a distinctive feature of NC patterns in other languages too, e.g. Hungarian (see especially Puskás 1998), and should not necessarily be collapsed with focus, as emphasized also in Szabolsci 181, Vinet 1998, and Suranyi 2002; see also our discussion in 2.3.1 and 2.3.4 of certain syntactic asymmetries between focused items and wh-owrds. (This doesn't mean, of course, that n-words cannot be focused on occasion; but this is indeed a limited phenomenon, as noted in Suranyi 2002).

As shown in the examples above, the co-occurrence of the SN is obligatory; but the sentences above are interpreted uniformly as containing a logical structure with only one negation. At a general level, then, n-words in NC can somehow 'be associated' with negative meaning, and the major task has been to identify what it means exactly to be able to do so. The most obvious possibility is, of course, to interpret association with negative meaning as equivalent to having inherent negative meaning. This possibility seems particularly attractive in view of the fact that $n$-words can contribute negative fragment answers; $n$-words have thus been treated as negative quantifiers, originally in Zanuttini 1991, and Haegeman and Zanuttini 1991.

In order to decide whether to pursue this hypothesis or not, we must consider one important fact: that when a language actually employs a negative quantifier, NC is systematically excluded, as in languages which do not employ NC as a rule, e.g. German, Dutch, and English (West Germanic), and Scandinavian languages. Germanic n-words, unlike n-words in NC structures, when co-occurring with a $\mathrm{SN}$, yield only a double negative reading:
a. Frank heeft niet
niemand gezien.
Dutch
Frank have.3sg not nobody seen
'It is not the case that Frank didn't see anybody.
\# Frank didn't see anybody. 
b. Frank did not see nobody.

c. Frank hat niemand gesehen.

English

German

The interpretation of these sentence is as in (5) below, which is derived by combining the meaning of a negative quantifier and negation.

$$
\begin{aligned}
& \lambda \mathrm{P} \forall \mathrm{x}[\text { person }(\mathrm{x}) \rightarrow \neg \mathbf{P}(\mathrm{x})](\lambda \mathrm{y} \neg \text { saw }(\text { Frank, } \mathrm{y}))= \\
& \forall \mathrm{x}[\text { person }(\mathrm{x}) \rightarrow \neg(\neg \text { saw }(\text { Frank, } \mathrm{x}))]
\end{aligned}
$$

Hence, the sentences entail that Frank did see somebody or everybody (depending on whether we exploit universal negation for negative quantifiers, as we did here, or existential negation, which is also possible; we discuss the issue later). This reading differs clearly from the one we have without negation, illustrated below. NC structures only have this reading (e.g. 2a).

$$
\begin{array}{ll}
\text { a. } & \text { Frank saw nobody. } \\
\text { b. } & \lambda \mathrm{P} \forall \mathrm{x} \text { [person }(\mathrm{x}) \rightarrow \neg \mathbf{P}(\mathrm{x})](\lambda \mathrm{y} \text { saw (Frank, } \mathrm{y}))= \\
& \forall \mathrm{x}[\text { person }(\mathrm{x}) \rightarrow \neg \text { saw (Frank, } \mathrm{x})]
\end{array}
$$

Negative quantifiers in Germanic languages are thus inherently negative. Hence, when we have an additional syntactic negation coming from $\mathrm{SN}$ as in (5), we have a second logical negation too. The question is: are n-words in NC languages identical to negative quantifiers in non-NC languages? If so, why is it that we have NC in the former-- with a reading not equivalent to (5) but to (6)-- but not in the latter?

At this initial stage it is instructive to consider that n-words need not be morphologically negative either-- although by employing the prefix $n$-, the term itself allows for the implication that part of the expression qualifying as an n-word will contain a morpheme morphologically recognizable as negative. It has often been observed in the relevant literature that this is not the case (see among others Laka 1990, Quer 1993, Déprez 1997, Giannakidou 1998, 2000, Rowlett 1998). For example, Italian niente, nessuno, and Serbian/Croatian nista do bear negative morphology but their Catalan, French, and Greek counterparts do not, or do so but not consistently. Catalan, for instance, has ningú 'n-person' but res 'n-thing', and French and Greek n-words lack negative morphology altogether. Negative morphology is, then, not a prerequisite for n-word status.

With these preliminaries, our discussion is organized as follows. In the next section, the central issues of the interpretation of structures with n-words are presented. First I give an overview of the core puzzles, and then we discuss the individual proposals. Once it is made clear what the predictions are of each individual proposal, we can proceed with the empirical complexity of NC and n-words in section 3. Our goal will be to test the empirical scope of NC theories and see to what extent they are applicable to certain data, and of course when they are not. In section 4 we examine the alleged negativity of n-words and show it to be problematic for most cases. Having reached the conclusion that n-words cannot be negative quantifiers, in section 5 we address the question of whether NC structures co-exist with existential polarity dependencies under negation. This question is important in trying to decide what logical structure n-words map onto: existential or universal negation. We will use the results of this section in order to construct a typology of n-words and their proper semantic characterization. We conclude in section 6 by summarizing the main findings.

\section{The interpretation of negative concord and the nature of n-words}

For a successful account of NC the proper semantic characterization of n-words is essential. We thus go back to the original question: should we grant negative status to n-words or not? This question corresponds to the following cluster of subinquiries: 
(a) The negative 'concord' question: If n-words are negative, then in NC we do have more than one occurrence of negation. But why do we end up interpreting only a single negation? This situation is in sharp contrast with Germanic negative quantifiers whose inherent negativity cannot be cancelled, as we saw, and which therefore do not exhibit NC. If n-words in NC are indeed negative, the very phenomenon itself constitutes an 'anomaly', and in order to explain it we must stipulate some special rule for NC languages which cancels out the extra negative meanings. We would further have to stipulate that this rule is not operative in Germanic languages since these do not exhibit NC. But why NC languages employ this rule but non-NC languages do not does not seem to follow from something more general in the grammar of these languages, and remains essentially an ad hoc premise.

(b) The diversity of interpretation question: If $n$-words are not negative, then what is their actual meaning and how do they end up giving negative fragment answers? It is a quite complex enterprise to try to answer the question of what the possible meanings of n-words are, because the set of expressions identifiable as n-words in various languages with $\mathrm{NC}$ is highly heterogeneous. Evidently, this complexity mirrors the logical complexity of general negative statements. As we see below, there are two possible logical structures that n-words can map onto:

\section{Logical representations of general negative statements}
(a) $\forall \mathrm{x}[\mathrm{P}(\mathrm{x}) \rightarrow \neg \mathrm{Q}(\mathrm{x})]$
(Universal negation)
(b) $\neg \exists \mathrm{x}[\mathrm{P}(\mathrm{x}) \wedge \mathrm{Q}(\mathrm{x})]$
(Existential negation)

The two formulae are truth conditionally equivalent; but the fact that these two options exist makes it plausible to hypothesize that some n-words would correspond to existential quantifiers under negation, some others to universal quantifiers, and some others perhaps to both. As we shall see, various implementations of these hypotheses have been proposed in the literature. Nwords have been argued to be indefinites or universal quantifiers. The former alternative is explored in, among others, Ladusaw 1992, 1994, Acquaviva 1993, 1997, Giannakidou 1997, Giannakidou and Quer 1995, 1997, Pinar 1996; Déprez 1997, 2000. The latter idea that some nwords are universals has been put forth in Giannakidou $(1998,2000)$, and is further supported by literature on Hungarian (Szabolsci 1981, Suranyi 2002 and references therein). N-words have also been characterized as underspecified in van der Wouden and Zwarts 1993, being compatible with both a negative quantifier and an existential quantifier meaning. This approach, essentially, acknowledges that $n$-words may be ambiguous between negative and non-negative meanings, a position that seems unavoidable, at least for some Romance n-words, as we conclude later in section 4 . Yet, there are empirical problems with the specific implementation in van der Wouden and Zwarts, noted in Giannakidou (1997:166-168), which we ignore here.

Crucially, another decisive factor is whether n-words may occur without the presence of the sentential negative marker, or whether the presence of the negative marker is obligatory in all contexts-- the later situation is known as 'strict' NC (Giannakidou 1998). In the non-strict varieties, and in the absence of $\mathrm{SN}$, it seems reasonable to hypothesize that the negative value comes from the n-word itself. Interestingly, in these varieties of $\mathrm{NC}$, n-words may give rise to double negation readings too, thereby supporting the hypothesis that they may be negative under one interpretation; but in strict NC languages double negation readings are never allowed.

(c) The locality question: A crosslinguistic feature of n-words and NC is that they are clausebounded (see especially Zanuttini 1991, Progovac 1988, 1994, Deprez 1997, Giannakidou 1998, 2000). This feature inspired an analysis of n-words as parallel to anaphors in Progovac 1988, 1994; but, most importantly, it suggests a close similarity between NC and quantifier scope, which is also known to be clause bounded. This characteristic is worth emphasizing because it prima facie argues against the plausibility of a non-quantificational analysis of $\mathrm{n}$-words as indefinites.

(d) The polarity question: In the early 90's there has been a debate as to whether n-words are 
negative quantifiers or NPIs (see especially Laka 1990 versus Zanuttini 1991). This debate inspired discussions in various Romance languages, and it relied on the assumption that being an NPI means 'being existential', instead of 'being licensed by negation'. This assumption has been shown to be unfounded in more recent discussions, where NC is treated as an instance of negative polarity: n-words, in this view, especially those in strict NC languages, are NPIs since they need negation to be licensed (see especially Progovac 1988, 1994, Ladusaw 1992, 1994, and Giannakidou 1997, 1998, 2000; Laka 1990 can also be seen as favoring this view). The HPSG analyses of NC (Przperkopski and Kupc 1997, Richter and Sailer 1998) also implement directly accounts of $\mathrm{NC}$ in terms of polarity. We will take this position for granted in the present paper and allow the underlying assumption that n-words in NC are NPIs.

The central problem is, as we said, the 'anomalous' character of $\mathrm{NC}$ : the fact that seemingly multiple negations are interpreted as a single negation. Ideally, we wouldn't like NC to be an anomaly; we want to be able to derive it from other, better understood, phenomena. The same desideratum applies, at a general level, to all polarity phenomena: we do not want to posit them in the grammar as composition external filters, but we want to derive them from rules that we need independently anyway; see Giannakidou 1998, 2001 for extensive discussion; also Tovena 1998). The reduction of NC to an indefinite or quantificational dependency should be seen as attempting to do precisely this.

Another attempt in the same spirit is Progovac $(1988,1994)$ who tries to reduce the principles governing NC to the principles of Binding theory. This reduction, though at first glance appealing, does not actually afford a better understanding of $\mathrm{NC}$ since it reduces one mystery-- NC-- to another one (the Binding theory), without offering an actual semantic characterization of n-words. We do not address this proposal here in any detail, but we will try to integrate Progovac's facts about Serbian/Croatian, which are in many ways significant, to the general approach we pursue in this paper.

Given the two logical options in (7), as well the option of inherent negativity, it seems simple-minded to expect a single interpretation for $\mathrm{NC}$ crosslinguistically; rather it is more reasonable to expect a family of interpretations to jointly accommodate the whole range of data. This is the stance we are taking here, in agreement with a research agenda originating in Ladusaw 1994 and further implemented in Acquaviva 1997, Giannakidou and Quer 1995, 1997, and Giannakidou 1997, 1998, 2000.

\subsection{Negative absorption}

Zanuttini (1991), Haegeman and Zanuttini (1991, 1996) and Haegeman (1995) view NC as an agreement phenomenon. They propose a quite influential account based on the assumption that n-words are negative quantifiers. In order to derive $\mathrm{NC}$, they invoke a special rule, negative absorption, inspired by Higginbotham and May's (1981) wh-absorption (whose current theoretical status, let it be noted, is being reconsidered under more recent discussions of multiple wh-dependencies; see for instance Reinhart 1997). The postulation of negative absorption on a par with wh-absorption presumes that NC and multiple wh-dependencies are instances of the same phenomenon which is also highly questionable, see especially Acquaviva 1995, 1997 and Giannakidou 1998 for discussion. At any rate, negative absorption has been proposed to allow any number of n-words and the SN to merge into one semantic negation (the NEG-criterion; Zanuttini 1991, Haegeman and Zanuttini 1991 and Haegeman 1995; for a slightly different variant formulated in terms of 'negative void' see Postma 1995).

$$
\begin{aligned}
& \text { Negative absorption rule } \\
& {[\forall \mathrm{x} \neg][\forall \mathrm{y} \neg][\forall \mathrm{z} \neg] \rightarrow[\forall \mathrm{x}, \mathrm{y}, \mathrm{z}] \neg}
\end{aligned}
$$

Multiple negative quantifiers amalgamate into a single negative quantifier. Syntactically, these structures contain just a single operator which can bind n-number of variables (just like in multiple wh-structures under wh-absoprtion). The NEG-criterion criterion has been restated recently in terms of feature checking in e.g. Brown 1999, Watanabe to appear, and Progovac in 
press. The idea is, for example, in Brown 1999, that n-words contain an uninterpretable neg feature that must be checked against the appropriate head-negation; for Watanabe, the relevant feature is a focus feature. Given that interpretability of features is still largely undefined in the current state of the theory, as well as the fact that, as we shall see later in section 5 , not all nword or NPI dependencies involve movement (in the sense of feature checking), I will stick here to the more classical version of the absorption approach.

Consider a sentence like the one below from Catalan with two n-words and SN: this sentence is assumed to contain a single negative quantifier which ranges over two variables:
a. No he dit res a ningú.
not have.1sg said $n$-thing to n-person
'I didn't say anything to nobody.'
b. $\quad$ No $\mathrm{x}, \mathrm{y}[\operatorname{thing}(\mathrm{x}) \wedge \operatorname{person}(\mathrm{y})][\operatorname{said}(\mathrm{I}, \mathrm{x}, \mathrm{y})]$

This analysis is generalized to a number of languages. Crucial to this analysis is the assumption that n-words are (syntactic) negative operators, hence semantically negative items. Zanuttini (1991), Haegeman and Zanuttini $(1991,1996)$ and Haegeman (1995) state that n-words in Romance and West Flemish are negative quantifiers. As such, n-words comprise a [+quantificational] and a [+negative] feature, where being [+quantificational] entails being a syntactic operator. Because n-words are quantifiers, their sentential scope must be syntactically derived by reaching a scope position at least by LF; being negative too, n-words must agree with a negative head. Both requirements are met by application of move- $\alpha$, which raises $n$-words to [Spec,NegP] or adjoins them to that position either at s-structure or at LF (but see Haegeman 1995 for the stronger claim that the NEG-criterion is uniformly satisfied at s-structure). ${ }^{3}$ Once nwords reach [Spec,NegP], they enter a Spec-Head relation with the negative head. In this analysis, the relevant part of (9a) would look at LF as either (10) or (11) depending on whether we assume raising to [Spec,NegP] or adjunction to NegP:
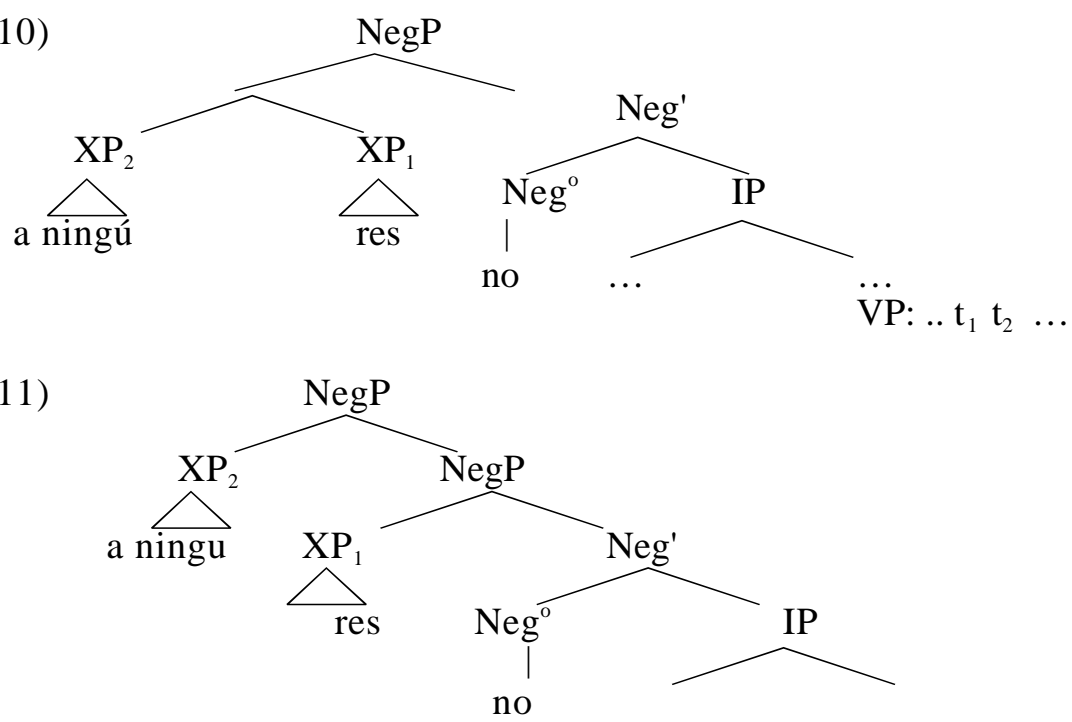

The driving force for such configurations is the NEG-criterion, a well-formedness condition which applies to all elements bearing the feature [+negative] and which determines their distribution and interpretation. It requires that such expressions check their negative feature against a head endowed with it. Based on the wH-criterion as formulated in Rizzi (1990), Haegeman and Zanuttini state the NEG-criterion in (12):

\section{The NEG-criterion}

a. A NEG-operator must be in Spec-head agreement relation with an $\mathrm{X}^{0}$ [NEG].

b. An $X^{0}$ [NEG] must be in Spec-head agreement relation with a NEG-operator. 
Additionally, the following definitions obtain:
a. NEG-operator: a negative phrase in a scope position;
b. Scope position: left-peripheral A'-position [Spec,XP] or [YP,XP].

In fact, the NEG-criterion may be regarded as a particular realization of a more general constraint, the AFFECT-criterion (cf. Rizzi 1990, Haegeman 1992). (12) tells us nothing about the phonological realization of $\mathrm{Neg}^{0}$, although the most plausible implementation of it would imply that the availability of $\mathrm{NC}$ must be linked to the realization of $\mathrm{Neg}^{0}$ (covert or overt), as in Zanuttini (1991); see also Moritz and Valois (1994). We saw, however, in footnote 2 that NC is allowed also with SN that are not heads but XPs. The negative head may be overt or covert, depending on language specific constraints. Strict NC languages like Greek, Catalan, and Slavic (where $\mathrm{SN}$ is obligatory) require that $\mathrm{Neg}^{0}$ be always overt. In languages where this does not hold like Italian, Spanish, and Portuguese such a requirement is absent. Evidently, the movement involved for the satisfaction of the NEG-criterion is an instance of $\mathrm{A}^{\prime}$-movement.

The detailed descriptions that will follow make it clear that the neg-criterion approach, posed in this generality, cannot be the correct analysis of NC. The underlying idea, which can be restated as negative quantifiers forming resumptive structures, may indeed be a useful one for a certain variety of NC - negative spread, which we discuss in section 3 . But there are at least three problems with the particular implementation we outlined here. First, the characterization of the general class of n-words as negative quantifiers will be questioned in section 4; we see there that there is very little evidence that n-words are negative in most variaties of NC. We can, of course, still maintain that $\mathrm{n}$-words are quantificational without being committed to negativity. This is indeed an appealing option, and is explored in various works (Deprez 1997, Giannakidou 1998, 2000, Puskas 1998, and others).

The second problem comes from the alleged uniformity between multiple whdependencies and NC and the reduction of the latter to the former. It has been emphasized numerous times in the literature that there are significant asymmetries between wh-dependencies and NC (see the references mentioned earlier). The discussion will not be repeated here, but we will take it as established that $\mathrm{NC}$ and wh-dependencies are distinct.

Finally, by invoking the special rule of negative absorption, whose role appears to be particular to NC, we have not succeded in getting rid of the anomalous character of NC. Instead, we have further established this anomalous character by reducing it to another 'special', hence also anomalous, mechanism: wh-absorption. Ideally, we would prefer a theory which derives the resolution of NC from a mechanism for which we have independent evidence in the grammar anyway.

\section{$2.2 \quad \mathrm{~N}$-words as indefinites}

The indefinites approach signals the first attempt to reduce NC to an independently motivated mechanism: that of indefinite binding. The approach was initiated in Ladusaw $(1992,1994)$ and was further developed in Acquaviva (1993, 1997), Giannakidou and Quer (1995, 1997), Giannakidou (1997), Déprez (1997, 2000), Richter and Sailer (1998), and others. The idea is that n-words are open formulae with no quantificational force of their own (Kamp 1981, Heim 1982). Like indefinites, n-words contribute a free variable and a predicative condition on that variable:

$$
\begin{aligned}
& {[[\text { uno studente }]]=\quad \begin{array}{r}
\text { student }(\mathrm{x}) \\
{[[\text { nessuno studente }]]}
\end{array}=\text { student }(\mathrm{x})}
\end{aligned}
$$

$\mathrm{N}$-words differ from regular indefinites in that they come with a roofing requirement ( Ladusaw 1992) which must be met at the sentence level. Roofing in Ladusaw is stated as a binding requirement: n-words must be bound by a semantically appropriate operator. In Giannakidou 
and Quer (1995, 1995), and Giannakidou 1997 this requirement is generalized to nonveridical operators. Negation, of course, is not strictly speaking a variable binder since it is not a quantificational operator ${ }^{4}$; roofing, then, is better rephrased as a requirement that existential closure apply under negation (Giannakidou 1998). So, for the sentence we just discussed in (9a), we will have the structure below:

$$
\neg\left[{ }_{\mathrm{VP}} \exists \mathrm{x} \exists \mathrm{y}(\operatorname{thing}(\mathrm{x}) \wedge \text { person }(\mathrm{y}) \wedge \text { said }(\text { he }, \mathrm{x}, \mathrm{y}))\right]
$$

The n-word variable is existentially closed in the scope of negation, i.e. in the VP. In Giannakidou (1997) it is further noted that this is the only level for application of existential closure; n-words, and other (negative) polarity indefinites can never be bound via text-level existential closure, as this would imply a wide scope reading with respect to negation, with the ensuing assertion of existence, which (negative) polarity indefinites do not have. In this account, the narrow scope of polarity indefinites and their polarity requirement are collapsed into the same source.

By assuming that $n$-words denote open formulae with no inherent quantificational force, the indefinites approach seems to offer an easy solution to the problem of NC: n-words do not contribute negation, only the SN does. This, however, turns out to be too easy a solution. The most obvious problem is that $\mathrm{n}$-words do not exhibit the quantificational variability characteristic of indefinites, which are unselectively bound by quantificational (Q-) operators, acquiring thereby the Q-force of their binders. When construed with Q-adverbs, for example, n-words are never bound by them; instead they seem to remain existentially closed under negation in the VP domain. This is illustrated in the following example from Greek:

(16) $\{$ Sixna/Pu ke pu $\}$, otan o Janis ine thimomenos, dhen milai me KANENAN. ' $\{$ Usually/Sometimes $\}$, when John is upset he talks to nobody.'
a. USUALLYs $\left[_{\text {Restr. }}\right.$ John is upset in s ] [ scope $\neg \exists x($ person $(x, s) \wedge$ talk $($ John, $\left.x, s))\right]$ b. SOMETIMESs $\left[_{\text {Restr. }}\right.$ John is upset in s] $\left[_{\text {Scope }} \neg \exists x(\right.$ person $(x, s) \wedge$ talk $($ John, $\left.x, s))\right]$

Here we have two Q-adverbs with varying Q-force, but the interpretation of KANENAN remains 'zero people' for each situation the Q-adverb quantifies over. Thus, the Q-adverb does not bind the n-word variable. If indefinites, then, in addition to the roofing requirement, n-words would have to have another 'special' feature: they cannot be bound by a Q-operator. But this is a striking feature, given that being bound by Q-operator is a very basic property that indefinites generally have. PI indefinites not related to negation, e.g. free choice indefinites, actually do exhibit Q-variability of the standard kind (Giannakidou 2001:701-703).

One may argue that a potential ambiguity between negative and existential interpretations is indeed a case of Q-variability. This might be, for example, a suitable analysis for Romance, as $\mathrm{n}$-words in these languages seem to be negative under negation but existential in non-negative environments (interrogatives, conditionals, restriction of $\forall$, etc.; to be discussed in section 4). Such an analysis, however, would still have to deal with the following two problems: first, not all n-words exhibit this ambiguity. Greek NC n-words, for instance, which are only licit under negation and antiveridical operators, are never interpreted as existentials. In fact, as we will in section 4, in contexts favoring this interpretation Greek n-words are ungrammatical (interrogatives, conditionals, restriction of $\forall$, etc); the same holds for Slavic and Hungarian nwords. On the other hand, we see in section 5 that there are n-words which are indeed interpreted existentially, roughly equivalent to any under negation, but these are interpreted only existentially, and hence there is no variability.

The second problem is that the derivation of the negative reading is non-compositional. If in the negative reading n-words involve $\forall$-force, $\forall$ must be stipulated compositional externally, because negation alone can surely not provide it. Given that $\forall \neg$ and $\neg \exists$ are truth conditionally equivalent, it makes more sense to say that there is actually no quantificational variability, and that n-words contribute $\exists$, which under negation, $\neg \exists$, will give the negative 
meaning. In a nonnegative context, the existential import of $\exists$ will be preserved. This squares neatly with our previous observation that $n$-word indefinites can only be bound by an existential quantifier under negation, and by no other Q-operator. But if this is so, then the 'indefinites' analysis is no longer about indefinites; it is about existential quantifiers, and it is this reinterpretation that we adhere to in the present paper.

Let us finally note that an existential approach to n-words will have trouble handling the issue of locality arising in NC; we see in section 5 that NC crosslinguistically is generally not licensed long-distance (Zanuttini 1991, Longobardi 1991, Progovac 1994, Giannakidou 1997 , 1998, 2000, Przepiorkowski and Kupc 1997, Brown 1999, among many others). If n-words were indefinites/existentials, it is surprising to find such locality constraints, as indefinites are generally thought to have 'unbounded' scope. In some cases even, e.g. in Polish and Russian, locality is very strict: $\mathrm{NC}$ is excluded from non-monoclausal domains, even if these domains are subjunctive-like or infinitival. The analysis of $n$-words as indefinites predicts that $n$-words will be licensed unboundedly as long as they remain in the scope of the licensing operator. Though this is true, as we shall see in section 5, of existential PIs under negation, e.g. any, it is clearly not true of n-words in NC.

\subsection{N-words and universal quantifiers}

A different line of reasoning is pursued in Giannakidou (1998, 2000). It is proposed that NC crosslinguistically must involve the two logically available possibilities: an existential and a universal construal. In a given language, the two construals may be realized by two different paradigms of n-words - as is the case in Greek-, but in others, a single paradigm may incorporate both meanings. This picture is recently supported by work on Hungarian in Suranyi (to appear), where it is shown that the two paradigms of Hungarian n-words actually have both interpretations each. In an earlier paper by Szabolcsi 1981, Hungarian n-words were uniformly analyzed as universals, which again supports the more specific argument that we need to allow for the universal quantifier option in the semantics of n-words crosslinguistically. Note also that certain languages, e.g. Hebrew, employ morphologically unversal n-word kol 'every', e.g. kol yeled nivdak 'Every child was examined', and lo (neg.) nimce'u kol maxalot 'No disease was found' (the data are from Mittwoch 2001:280). Obvioulsy, then, the hypothesis that there may be universal n-words is empirically well motivated. Significant motivation comes also from the parallelism between n-words and universal quantifiers in terms of their scope possibilities, which is what we consider first.

\subsubsection{Universal quantifiers and n-words: parallelism in scope}

In this section, we examine the scope parallelisms between n-words and universal quantifiers which support the hypothesis that $n$-words are universal quantifiers. The locality involved in $\mathrm{NC}$, namely clause-boundedness, will be shown to be identical to the locality in quantificational dependencies. For simplicity, we concentrate on one language: Greek.

The first observation is that $\mathrm{n}$-words in $\mathrm{NC}$ are generally not licensed long-distance. This is a crosslinguistic feature of NC, which we return to later (section 5.1). Greek lacks infinitives, but has three types of complement clauses: oti, $n a$, and $p u$ clauses. Oti is the indicative nonfactive complementizer and $p u$ is the indicative factive one. $N a$ introduces subjunctive clauses, but it is not a complementizer (Philippaki-Warburton 1993 and references therein). $\mathrm{Na}$-domains in Greek usually behave on a par with infinitival and 'restructuring' domains of other languages (Aissen and Perlmutter 1983), which are known to be 'transparent' with respect to certain long distance dependencies (for reasons immaterial here). Greek n-words are not accepted in indicative complements of negated matrix predicates. $\mathrm{NC}$ is possible only in monoclausal domains and subjuncive $n a$-clauses: 

a. * O Pavlos dhen ipe [oti idhe KANENAN]. the Paul not said.3sg that saw.3sg n-person (Paul didn't say he saw anybody.)
b. * Dhen lipame [pu pligosa KANENAN]. not be-sorry.1sg that hurt.1sg n-person (I don't regret that I hurt anybody.)
c. O Pavlos dhen theli [na dhi KANENAN]. the Paul not want.3sg subj see.3sg n-person
'Paul doesn't want to see anybody.'

This situation contrasts clearly with wh-dependencies which are freely allowed through oti complements, and partly through $p u$ complements, which are weak islands (pace Roussou 1994, Varlokosta 1994). The details are presented in Giannakidou 1998, 2000, but the basic fact is illustrated here:
a. Pjon 1 ipe Pavlos oti idhe $t_{1}$ ? who said.3sg the Paul that saw.3sg 'Who did Paul say that he saw?' who was-glad.3sg the Paul that saw.3sg 'Who was Paul glad that he saw?'
b. $\quad$ Pjon $_{1}$ xarike o Pavlos pu idhe $t_{1}$ ?

Hence NC is clearly not a wh-dependency - it is also not a focus dependency, as in situ focus is indeed sanctioned through $p u$ and oti complements:
a. Milises me ti jineka
[pu pandreftike PJON?]
talked.2sg with the woman who married.3sgWHO
'You talked to the woman who married who?'
b. Milises me ti jineka [pu pandreftike to JANI] talked.2sg with the woman who married.3sg the John 'You talked to the woman who married JOHN.'

More detailed discussion of the asymmetries between focus and NC are found in Giannakidou 1998. What we note here is that the long-distance pattern we observe with NC cannot be reduced to that of wh-movement or focus. Giannakidou and Quer 1995, 1997 further show that the Greek picture describes correctly the facts in Spanish-see also Progovac 1994 for the observation that Serbian/Croatian n-words are licensed only in subjunctive clauses, and Zanuttini 1991 for Italian. Catalan n-words can be licensed in indicative clauses too, licensing existential readings- we return to the significance of this fact in section 5.1.

The second thing to note is that the generalization that $\mathrm{NC}$ is licensed long-distance only in subjunctive complements can occasionally be violated: n-words may appear in the indicative complements of epistemic neg-raising verbs, e.g. in the oti complement of pistevo 'believe':

$\begin{array}{lcl}\text { Dhen pistevo } & \text { [oti idhes } & \text { KANENAN]. } \\ \text { not believe.1sg } & \text { that saw.2sg } & \text { n-person } \\ \text { 'I don't believe you saw anybody.' } & \end{array}$

$\mathrm{N}$-word licensing in the complements of epistemic neg-raising verbs is generally very weak, and subject to performativity constraints, i.e. person (the embedding predicate must be 1st person singular), and tense constraints (only present tense is acceptable), as is shown in Giannakidou and Quer (1995, 1997:106-111) and Giannakidou (1997), where the availability of cases like (21) was linked to the parenthetical uses of neg-raising verbs (for a general discussion of negraising, see Horn 1978). If pistevo is modified by an adverb, neg-raising is blocked, and so is $\mathrm{NC}$, because adverb modification forces the attitudinal reading. The fact is first observed in Veloudis 1982, where there is extensive discussion of the interaction between n-words and neg- 
raising.

Dhen pistevo adhikeolojita oti me apata.
not believe.1sg unreasonably that me cheat.3sg
'I don't believe unreasonably that (s)he is cheating me. '
\# I believe unreasonably that (s)he isn't cheating me.
*Dhen pistevo adhikeolojita oti idhes
not believe.1sg unreasonably that saw.2sg n-person
(I don't believe unreasonably that you saw anybody.)

Since adhikeolojita in (23) is an attitude modifier, pistevo cannot be used parenthetically. As a result, $\mathrm{NC}$ is not possible; compare this sentence to (21), without the adverb.

Crucially, adverbs exhibit exactly the same blocking effect with quantifier scope. As shown in Farkas and Giannakidou (1996), para poli 'very much' prevents kathe 'every' from taking scope over kapjos 'some' in (24), although this is possible in (25), without the adverb; ">" reads as "scope over":

a. Kapjos kathijitis ithele para poli kathe ipopsifios s' afti ti lista some professor wanted.3sg very much every candidate in this the list na vri dhulja.

subj find.3sg job

'Some professor wanted very much every candidate on this list to find a job.'

b. $\quad \exists>\forall$

c. $\quad * \forall>\exists$

a. Kapjos kathijitis ihele kathe ipopsifios s' afti ti lista na vri dhulja. some professor wanted.3sg every candidate in this the list subj find.3sg job

b. $\quad \exists>\forall$ 'Some professor wanted every candidate on this list to find a job.'

c. $\quad \forall>\exists$

Example (25) can be true in a situation in which professors co-vary with students (e.g. if we have excellent recommendation letters for each student candidate). This indicates that kathe ipopsifios 'every candidate' scopes over the existential kapjos kathijitis 'some professor'. Sentence (24) lacks this reading: only one, very hopeful, professor is involved.

Related to this is a third fact: that universal quantifiers cannot scope beyond the clause they occur in, unlike indefinites, for instance, which can scope freely through one or more clause boundaries, or wh-phrases. Universal quantifers cannot cross the tensed clause boundary (for discussion see Farkas and Giannakidou 1996, Reinhart 1997). Exceptions to this generalization were presented in Farkas and Giannakidou 1996 involving $n a$-clauses, which we discuss next; the effect can be reproduced in Romance and English with restructuring or infinitival domains.

Farkas and Giannakidou observe that universal quantifiers, i.e. kathe, can indeed scope over an indefinite in the main clause as long as it is found in a $n a$-complement. From a $p u$ or oti complement, kathe cannot take wide scope:

a. Kapjos kathijitis frondise kathe fititis s'afti ti lista na vri

dhulja. some professor made-sure.3sg every student in this the list subj find.3sg job

b. $\quad \exists>\forall$

c. $\quad \forall>\exists$

a. Kapjos fititis lipithike pu kathe kathijitis tis sxolis apolithike. some student was-sorry.3sg that every professor the department got-fired.3sg 'Some student regrets that every professor in the department got fired.'

b. $\quad \exists>\forall$

c. $\quad * \forall>\exists$ 

a. Kapjos fititis ipe oti kathe kathijitis tis sxolis apolithike. some student said.3sg that every professor the department got-fired.3sg 'Some student said that every professor in the department got fired.'
b. $\quad \exists>\forall$
c. $\quad * \forall>\exists$

The $n a$-sentence in (26) has a reading in which professors co-vary with students (as in the scenario mentioned above where there are different recommendation letters for each candidate); the sentences in (27) and (28) lack this reading, as indicated. Farkas and Giannakidou propose certain semantic constraints to account for what allows for wide scope, not of immediate relevance here. What matters is that we may assume safely that the following holds:

\section{Clause-boundedness of universal quantifiers}

The scope of $\forall$ is clause-bounded, except when $\forall$ occurs in an infinitival (or restructuring) domain.

But this is exactly the constraint we observed with NC in (18): NC is clause-bounded and possible long-distance only across $n a$-complements; hence NC is clause-bounded in the way the scope of universal quantifiers is. The type of locality involved in NC, then, strongly implicates a quantificational dependency. Note that this conclusion is not necessarily an argument for Quantifier Raising (QR), although it is implemented as application of QR in Giannakidou 1998, 2000. The generalization can be cast also in a system where quantifers do not move; for an attempt to implement this idea as an instance of non-movement AGREE (Chomsky 2000), see Giannakidou and Merchant 2002.

\subsubsection{Negative concord as a universal scoping above negation}

Greek n-words are universal quantifiers, which are additionally polarity sensitive-- since they need negation to be licensed. In the framework of polarity we are assuming, NPI-universals come with a sensitivity requirement which makes them different from non-sensitive universals: unlike these, which can combine with both positive and negative predicates, NPI-universals can only combine with negative (i.e. antiveridical) predicates. Just like in other polarity dependencies discussed in Giannakidou (1998), this distinctive feature must be encoded in the grammar as a type difference between non-sensitive universals and their NPI-counterparts. ${ }^{5}$

As NPIs, NPI-universals require the presence of negation, but they must move in a scope position above negation. This movement is motivated by (a) their sensitivity requirement to combine with an antiveridical predicate, and (b) the need to yield the correct interpretation for $\mathrm{NC}$ as $\forall \neg$, which is the only reading NC structures have. ${ }^{6}$

Consider now the following core sentences, and their respective interpretations. Since

Greek is a VSO language, the orders are natural and quite common. Overt movement of emphatics is also allowed (and must be analyzed as topicalization, as we will see later in 2.3.4).

$$
\begin{aligned}
& \text { Dhen irthe KANENAS. } \\
& \text { not came.3sg n-person } \\
& \text { 'Nobody came. ' } \\
& \text { Dhen ipe o Pavlos TIPOTA. } \\
& \text { not said.3sg the Paul n-thing } \\
& \text { 'Paul said nothing. ' } \\
& \forall x \text { [person }(x) \rightarrow \neg \text { came }(x)] \\
& \forall x[\text { thing }(x) \rightarrow \neg \text { said }(\text { Paul, } x)]
\end{aligned}
$$

The n-word is interpreted above negation, resulting in a universal negative statement. 
Since we are dealing with quantifiers, the obvious way to derive this reading is to assume that KANENAN and TIPOTA undergo QR and scope above negation. Note that non-sensitive universal quantifiers like kathe 'every' cannot scope over negation from a VP-internal position. This fact has been noted for a number of languages (see Beghelli and Stowell 1997 for discussion; and Giannakidou 2000: 499-501, for an explanation of the contrast by invoking the Elsewhere principle of Kiparksy 1973).

Given that negation precedes the emphatics in the linear order, we must assume that the universal-over-negation reading is achieved by QR at LF. The proposed LFs are given below; for the '.'convention see Heim and Kratzer (1998); some irrelevant intermediate steps are suppressed.

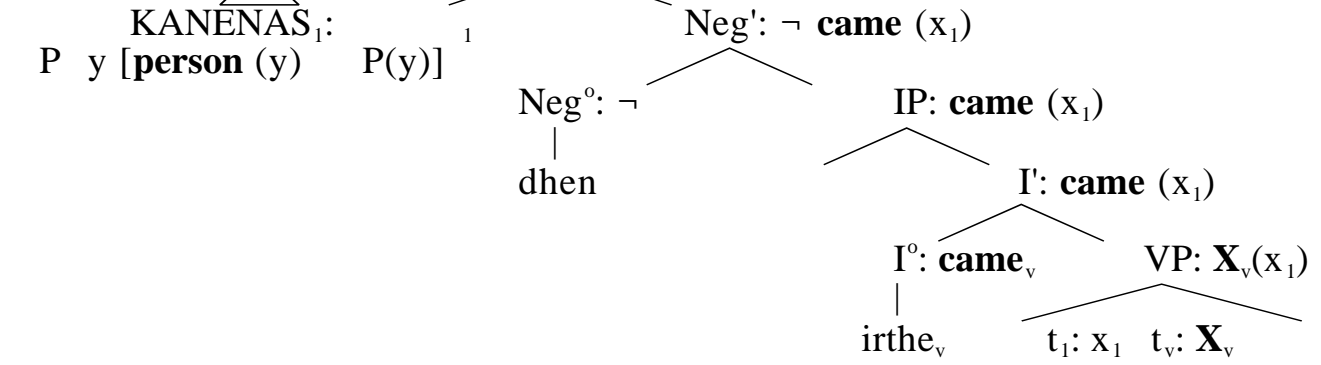

NegP: $\lambda \mathrm{P} \forall \mathrm{y}$ [thing $(\mathrm{y}) \rightarrow \mathrm{P}(\mathrm{y})]\left(\lambda \mathrm{x}_{1} \neg\right.$ said $\left(\right.$ Paul, $\left.\left.\mathrm{x}_{1}\right)\right)=$

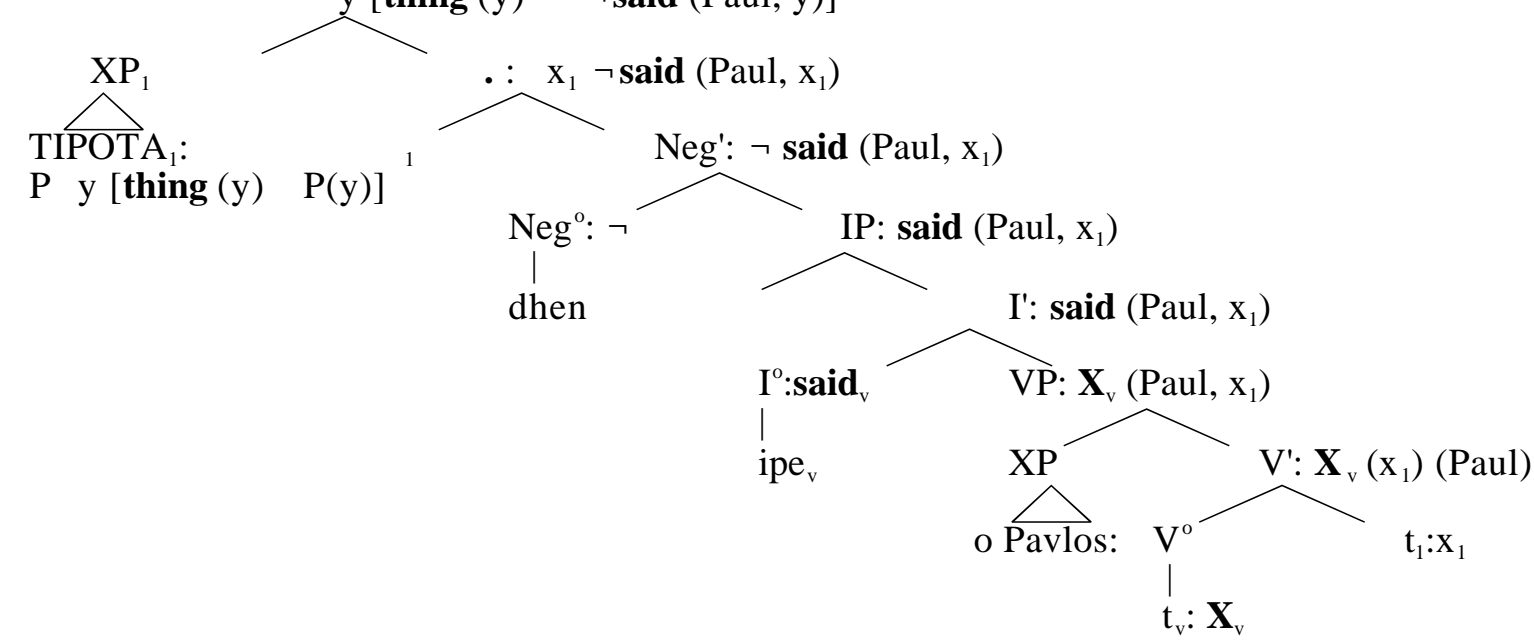

In such configurations, KANENAS and TIPOTA undergo QR past dhen and land in [Spec, NegP], though an orthodox implementation of QR as adjunction (May 1985), in this case to NegP (or just IP, if one wishes to analyze dhen as a clitic), is equally conceivable. In either case, emphatics are interpreted outside the scope of negation, arriving at the desired logical representations. Nothing specific to NC such as absorption needs to be stipulated. Multiple occurrences of emphatics require successive adjunctions to NegP (or multiple specifiers as in Chomsky 1995; nothing crucial seems to rely on this choice).

The analysis presented above has one thing in common with the NEG-criterion approach: it proposes movement of the $n$-word to [Spec,NegP]. Yet, unlike the NEG-criterion, this analysis does not rely on the existence of $\mathrm{NegP}$, and can be cast, as mentioned above, also in terms of adjunction to IP, if one does not want to postulate $\mathrm{NegP}$, for example, or in order to account for $\mathrm{NC}$ with without, where there is no overt negation. In the context of NegP, the motivation of the 
movement to [Spec,NegP] in this analysis differs substantially from that in the proposals insipired by the NEG-criterion. In these approaches, the $n$-word moves in order to undergo absorption (or check its negative feature). In the account presented here, n-word movement to $[\mathrm{Spec}, \mathrm{NegP}]$ is motivated by the correct interpretation of $\mathrm{NC}$.

Additionally, this analysis seems to work independently of the syntactic status of the NM (whether it is the head or the specifier of NegP). Hence, unlike accounts based on the NEGcriterion, this proposal captures correctly the fact that NC arises with both $\mathrm{X}^{0}$ and XP SNs (cf. $\S 1$ ), without further adjustments.

\subsubsection{Commitment of existence}

The analysis of $n$-words as universal quantifiers predicts that universal n-words will give rise to an existential inference, just like universal quantifiers usually do. The issue is discussed extensively in Horn 1997, where it is shown that universal statements are not like regular conditionals which can be true also in case the antecedent is false. Rather, we tend to interpret universal quantifiers with non-empty restrictions: for example, we tend to evaluate Every student left as true only in a context where there are students; a continuation like but there are no students is highly disfavored (though not impossible, especially if instead of an episodic past tense we have a modal verb; see Giannakidou 1999:401-404 for discussion). With some universals, the existence condition is a presupposition, e.g. with both and each. We need not address at present the issue of what exactly the nature of these existence inferences with universals is; we will just refer to them as existential commitments, following Horn.

The presuppositional nature of existence with universals become visible with negation:
a. \# I Cleo dhen idhe kathe the Cleo not saw.3sg every monokero. \#Cleo did not see every unicorn. unicorn
b. $\quad \neg[\forall \mathrm{x}$ unicorn $(\mathrm{x}) \rightarrow$ saw $($ Cleo, $\mathrm{x})]$

The sentence is odd, in Greek as well as in English. The source of oddity is that we presume that the restriction of the universal is non-empty, that is, that there are unicorns in the actual world, and this is a bizarre thing to assume.

Unlike universals, existential quantifiers do not express existential commitment under negation. The sentence below is fine, and can be continued with something like "because unicorns don't exist":
a. I Cleo dhen idhe enan monokero. the Cleo not saw.3sg a unicorn 'Cleo did not see a unicorn.'
b. $\neg \exists \mathrm{x}[$ unicorn $(\mathrm{x}) \wedge$ saw $(\mathrm{Cleo}, \mathrm{x})]$

In the light of this contrast, the hypothesis that some n-words are universal predicts that those nwords will resemble other universal in presupposing, or being associated to, existence. Consider the sentences below, with an extensional and intensional verb:

$$
\begin{array}{ll}
\text { a. } & \text { \# I Cleo dhen idhe KANENA monokero. } \\
\text { the Cleo not saw.3sg n- } & \text { unicorn } \\
\text { 'Cleo saw no unicorns.' } & \\
\text { b. } & \forall \mathrm{x}[\text { unicorn }(\mathrm{x}) \rightarrow \neg \text { saw }(\text { Cleo, } \mathrm{x})] \\
\text { a. } & \text { \# I Cleo dhen psaxni } \\
& \text { the Cleo not seek.3sg } \\
& \text { 'Cleo seeks no unicorns.' } \\
\text { b. } & \forall \mathrm{x}[\text { unicorn }(\mathrm{x}) \rightarrow \neg \text { seek }(\mathrm{Cleo}, \mathrm{x})]
\end{array}
$$


These sentences are as odd as (36), and for exactly the same reason: we are forced to commit ourselves to existence of unicorns, which is of course an odd thing to do. Hence the sentences above support the assumption that emphatic n-words are universals and not existentials. (Note that the scope with respect to negation doesn't really matter, as existence commitment with regular universals survive despite the fact that the universal is interpreted under the scope of negation and not above it, as is the case with n-words).

Existential PIs (called nonemphatics; to be discussed more extensively in section 5), and bare NPs do not give rise to existential commitment, as expected. The following sentences are fine since we are not forced to question the speaker's grasp of the actual world:

$$
\begin{aligned}
& \text { a. I Cleo dhen }\{\text { idhe/ psaxni }\} \text { kanena monokero. } \\
& \text { the Cleo not saw.3sg/ seek.3sg n- } \quad \text { unicorn } \\
& \text { 'Cleo didn't see any unicorns.' } \\
& \text { 'Cleo isn't looking for any unicorns.' } \\
& \text { b. I Cleo dhen }\{\text { idhe/ psaxni }\} \text { monokerus. } \\
& \text { the Cleo not saw.3sg/ seek.3sg unicorns } \\
& \text { 'Cleo didn't see unicorns.' }
\end{aligned}
$$

The contrast between emphatics and nonemphatics/bare plurals we observe is in accordance with the position defended in Giannakidou $(1997,1998)$ that nonemphatics are interpreted as existentials inside the scope of the licensing operator. Bare NPs too are known to take narrow scope with respect to other operators (see Carlson 1977).

Finally, consider construals of emphatics with modal verbs like (41):

Dhen epitrepete na apolisun KAMIA nosokoma.

not is-allowed subj fire. $3 \mathrm{pl} \mathrm{n-}$ nurse

'They are allowed to fire no nurse.'

In construals with negative quantifiers and intensional verbs, sentences like the English translation of (41) - and especially their Dutch (geen) and German (kein) counterparts-- , are known to give rise to the three readings below (see Jacobs 1991, von Stechow 1993, Rullmann 1995, de Swart 1996):
a.
For each nurse $x$, one is not allowed to fire $x$.
b. What one is allowed to do is not fire any nurses.
c. One is not allowed to fire any nurses.
(wide scope)
(narrow scope)
(split)

The three readings are truth conditionally distinct. The reading in (42b) is rather marginal without the appropriate context. On the wide scope reading, we talk about a particular set of nurses and one is not allowed to fire those nurses. On the so-called split reading, on the other hand, we do not talk about a particular set of nurses. Sentences with this reading are true if firings are about some nurse or other. The availability of the split reading has been taken to argue in favor a decompositional analysis of negative quantifiers as $\neg \exists$, as in this reading the modal operator is interpreted in between negation and the existential quantifier (but see our discussion in 5.2.4 regarding the contrast between German and Dutch, on one hand, and English on the other).

Crucially, the Greek sentence in (41) has only one reading: the wide scope one. The other two readings, where negation and the intensional operator take wide scope over the quantifier, are excluded. This is precisely what the analysis of universal n-word predicts. (As expected, bare plural and nonemphatic construals are only interpreted narrow scope, or with the split reading). 


\subsubsection{Existence, familiarity, and topicalization}

In agreement with the existence commitment, universal n-words exhibit the property of familiarity. The notion is the one from Heim's file change semantics (Heim 1982): a quantifier is familiar if it carries an index which is already present in the files representing the previous discourse. Familiar quantifiers are thus presuppositional, i.e. they pick up discourse referents whose existence is previously established. Definite NPs prototypically denote familiar quantifiers, but universal quantifiers have also been taken to refer to familiar discourse referents, only in their case the discourse referent is a set rather than an individual (Kamp and Reyle 1993, Szabolcsi 1997). From a universal n-word, then, we expect familiarity; and this fact makes universal n-words prime candidates for topics, which can also undergo syntactic topicalization. These expectations are indeed borne out, as shown in Giannakidou 1998, 2000. In this section we briefly summarize the core facts, also because they make very clear predications crosslinguistically.

Consider the standard case below and its assigned semantic structure:
a. Dhen agorasa
KANENA vivlio.
not bought.1sg n- book
$\begin{array}{ll}\text { b. } & \forall \mathrm{x} \text { [book }(\mathrm{x}) \rightarrow \neg \text { bought }(\mathrm{I}, \mathrm{x})]\end{array}$

Negative sentences with emphatic n-words have constrained distribution: they cannot be uttered just out of the blue. Those with existential/indefinite PIs, however, though truth conditionally equivalent, can be used more freely and pose no requirement on the initial context, as we realize when we think of the respective sentence with any. The following two examples illustrate what it means to pose restrictions on the initial context:

\section{Context 1.}

Background: A: You were shopping all day. Did you buy anything? Clothes? Books? Records?

$\begin{array}{lll}\text { B: } & \text { a. \# A, oxi. Dhen aghorasa } & \text { KANENA vivlio. } \\ & \text { oh no Not bought.1sg n- book }\end{array}$

b. A Oh, no. I bought no books. Dhen aghorasa kanena vivlio.

oh no Not bought.1sg n- book

'Oh, no. I didn't buy any books.'

In the background of this context, no reference to a particular set of books is established; the mentioning of books happens in a non-declarative sentence, hence no set of books is introduced in the set of files representing the common ground. In such a situation, the use of the emphatic $\mathrm{n}$-word is totally inappropriate. Only the use an existential paradigm is felicitous-- the nonemphatic kanena vivlio, equivalent to any under negation (to be discussed shortly in section 5). The contrast supports the assumption that universal n-words denote familiar objects, unlike indefinite n-words which are standardly analyzed as novel (Heim 1982).

\section{Context 2.}

Background: A: I remember you told me about those books that you saw at the "Griekse Eiland". You wanted to buy them, right? What happened? Did you buy them after all?

B: a. A,oxi. Piga ke ta idha, ala dhen aghorasa (telika) KANENA vivlio. Oh, no. I went at looked at them but I bought no book after all.

b. A, oxi. Piga ke ta idha, ala dhen aghorasa (telika) kanena vivlio.

Oh, no. I went and looked at them, but I didn't buy any book after all.

Unlike in Context 1, in Context 2, reference to a set of books has been established in the 
background. This renders the utterance with the emphatic felicitous. As expected, the statement with the existential $\mathrm{n}$-word is fine too.

Denoting familiar entities, universal n-words can actually undergo topicalization. Definite NPs are what we would consider 'prototypical' topics, since they are the prototypical familiar NPs; indefinites and weak NPs (in the sense of Milsark 1974), on the other hand, cannot be used as topics because they carry novel indices, i.e. they introduce objects in the discourse rather than presupposing them. Indefinites can be used as topics only if novelty is suspended, as it happens when indefinites are interpreted as partitives.

Since universal quantifers denote familiar discourse entities they can easily be used as topics, and even undergo syntactic topicalization across languages (for discussion and references see Giannakidou 2000; Cinque 1990, Rizzi 1997). We witness this in the clitic left dislocation (CLLD) examples below, where the universal object quantifiers appear in a left peripheral topic position, and they are linked to clitics in the base position:
Kathe dhema to paredhosa
ston paralipti tu.
Greek
every parcel it delivered.1sg
in-the recipient its
'As for every parcel, I delivered it to its recipient.'
Tutti i tui libri, li ho rimesso al posto. Italian all your books, them have.1sg put-back in place
'As for your books, I put them back to their place.'

In the above cases, the quantifier phrase is 'rich' in descriptive content: it is either a modifier/determiner, or additional modifers are used; bare quantifiers cannot be topicalized (Giannakidou 1997, 1998, Anagnostopulou 1997):

$$
\begin{array}{ll}
\text { * Kathena, } & \text { ton idha. } \\
\text { everybody } & \text { him saw.1sg }
\end{array}
$$

Greek

The requirement for rich descriptive content is not a mystery; rich descriptive content helps us indentify the discourse referent. This seems to be necessary for universal quantifiers, because otherwise, the universal quantifier picks up a set too large for a proper discourse referent. Crucially, emphatic n-words can also be left dislocated and co-indexed with clitics:

$$
\begin{aligned}
& {[\text { KANENAN fititi }]_{1} \text { dhen }\left(\text { ton }_{1}\right) \text { idha na erxete stin ora tu. }} \\
& \text { n- student not him saw.1sg subj come.3sg on time his } \\
& \text { 'I saw no student arriving on time.' } \\
& \text { [ KANENA apo ta vivlia }]_{1} \text { dhen to }_{1} \text { agorasa telika. } \\
& \text { n- from the books not it bought.1sg finally } \\
& \text { 'I bought none of the books after all.' }
\end{aligned}
$$

The presence of the clitic is not obligatory-but in itself, the fact that emphatic n-word preposing allows clitics argues for a topic analysis of these, and against an assimilation of such structures to focus preposing which strictly requires a gap in the base position (Tsimpli 1995). The appearance of the clitic is again sensitive to the richness of the descriptive content of the preposed emphatic or the sentence predicate. As we see in (49), bare emphatics are incompatible with clitics:

$$
\begin{aligned}
& \text { * } \text { KANENAN }_{1} \text { dhen ton } \\
& \text { n-person idha. } \\
& \text { 'Nobody I saw.' }
\end{aligned}
$$

A parallel is observed in the preposing of Italian n-words. As noted in Rizzi (1997), bare nessuno cannot be coindexed with a clitic, but if we enrich its descriptive content and combine it with a relatively "heavy" predicate, clitics become fine: 
* Nessuno l' ho visto.

Nessuno \{di loro/ in questo dipartimento $\}$ l' ho visto parlare con Maria. n-person of them / in this department him have.1sg seen talk with Maria 'I saw \{none of them/no-one in the department $\}$ talking to Mary.'

The above contrasts are consonant with the idea that n-words can be used as topics. We will not pursue the matter in more detail here; see Giannakidou 1998, 2000 for additional diagnostics supporting this conclusion.

\subsubsection{Summary}

The theory implemented in Giannakidou 1998, 2000 proposes a 'pluralistic' view of NC, where n-words can be either universal or existential, or ambiguous between the two readings. A number of novel diagnostics are offered for universality, which we summarize here in points (a), (b) and (c). In section 5, we augment this list with the diagnostics in (d)-(f).

(52) Diagnostics for universal n-words

A universal n-word has the following properties:

(a) It is licensed only by local negation; long distance licensing may be allowed only through an infinitival or subjunctive clause.

(b) It expresses existential commitment, i.e. we tend to interpret it with a non-empty restriction.

(c) It can be used as topic in topicalization structures. It these cases it may be coindexed with a clitic pronoun (or a pronoun performing the respective function, if a language does not employ clitic pronouns).

(d) It can be modified by modifiers corresponding to almost/absolutely.

(e) It cannot bind donkey pronouns.

(f) It cannot be used as predicate nominal.

In section 5 we will further review a number of tests for existential import of n-words. The predictions for other languages are, then, clear, and we should be able to use the proposed diagnostics in order to trace the relevant Q-force of a given n-word paradigm.

Notably, the theory does not predict that all n-words will exhibit the features of the Greek ones-- on the contrary, because we acknowledge that negative statements can also exhibit an underlying existential structure, we expect languages to realize this option too. In such languages, however, n-words will behave differently with respect to the diagnostics above. We see, for example, that Slavic n-words, e.g. Polish, Russian and Serbian, exhibit a mixed behavior in satisfying criteria (a), (d), and (e), and partly (b), but at the same time, they violate (f) and can occur as predicate nominals, or they do not always give rise to existence commitments. (The topicalization test still needs to be checked.) Suranyi 2002 further notes that Hungarian n-words can be presuppositional and non-presuppotional, depending on the syntactic position they are found, a finding also supporting the pluralistic view on $\mathrm{NC}$ that we presented here.

Having familiarized ourselves with the theoretical options for n-words and NC, we can now illustrate of the empirical picture. We will see that for the correct interpretation of n-words we need two basic options: n-words can be either universal quantifiers or existential ones. In certain positions they can also receive a negative meaning, primarily in the preverbal position or in negative spread; but this happens only with a subset of n-words, mainly in Romance languages.

\section{Two basic varieties of negative concord and the distribution of n-words}


A central division in the description of NC is that between 'strict' $\mathrm{NC}$ and non-strict $\mathrm{NC}$ (Giannakidou 1998). In this section we illustrate the distinction which we will use as a guide, for the taxonomy of n-words in section 3.2.

\subsection{Strict and non-strict varieties of negative concord}

Strict NC varieties always require the presence of SN; in (2) we saw examples of this variety. It does not matter whether the n-word is a subject, object, or adjunct, or whether it is preverbal or postverbal. In strict NC varieties, the presence of SN is obligatory. We illustrate this below with examples from Serbian/Croatian (Progovac 1994:40,41) and Greek:
a. $\quad$ Milan *(ne) vidi nista.
Milan not see.3sg n-thing
'Milan cannot see anything.'
b. Milan nikada*(ne) vozi.
Milan n-when not drive.3sg
'Milan never drives.'

Serbian/Croatian; Progovac 1994:40, 41
a. O Petros * (dhen) idhe TIPOTA.
Greek
the Peter not saw.3sg n-thing
b. $\quad$ O Petros POTE *(dhen) odhiji.
the Peter n-ever not drive.3sg
'Peter never drives.'

Besides Greek and Serbian/Croatian, all other Slavic languages, as well as Hungarian, Romanian, and Japanese exhibit the property of strict NC. Even in structures with multiple nwords the presence of SN is obligatory, as we see in the examples below (from Giannakidou 2000, Przepiórkowski and Kupc 1998, Puskás 1998, and Watanabe to appear, respectively):

$\begin{array}{ll}\text { KANENAS *(dhen) ipe TIPOTA. } & \text { Greek } \\ \text { n-person not said.3sg n-thing } & \\ \text { 'Nobody said anything.' } & \text { Polish } \\ \text { Nikt } \quad \text { (nie) uderzyl nigogo. } & \\ \text { n-person not hit.3sg n-person } & \text { Hungarian } \\ \text { 'Nobody hit anybody.' } & \\ \text { Balázs *(nem) beszélt } \quad \text { senkivel semmiröl. } & \\ \text { Balázs not spoke.3sg n-person n-thing } & \\ \text { 'Balázs didn't talk about anything with anybody.' } & \text { Japanese } \\ \text { Dare-mo nani-mo iwa-nak-atta. } & \\ \text { n-person n-thing say.neg.past } & \end{array}$

Hence Greek, Hungarian, Japanese, and Slavic languages form a natural class in terms of strict $\mathrm{NC}$, and require the $\mathrm{SN}$ even when more than one $\mathrm{n}$-word occurs in a sentence. Strict NC structures never receive double negation readings, as emphasized in the studies just mentioned.

The situation in Romance is quite different: the presence of SN is not obligatory, and two n-words may co-occur in the absence of it, as in the sentences below. This variety of NC is known as 'negative' spread (den Besten 1986).
letto niente.
n-person have.3sg read n-thing
Italian
b. Nadie dijo nada.
Spanish 

n-person said.3sg n-thing
'Nobody said anything.'
c. Ningú va dir res.
n-person aux.3sg say n-thing
'Nobody said anything.'
d. Ninguem viu nada.
n-person saw.3sg n-thing
'Nobody saw anything.'
Catalan
Portuguese

Crucially, if we insert SN in languages above we get a double negation reading; but Romanian and Catalan seem to be an exception to this. Catalan in particular allows optionally for SN with a NC (single negation) reading:
Cap estudiant (no) va dir res.
n-student not aux.3sg say n-thing
'No student said anything.'

There are more subtle details to be addressed here. The most important one to note is that although negative spread is fine with 'bare' n-words, i.e. n-words as independent NP constituents, it seems to be disallowed when n-words are used as modifiers or determiners. The fact has been noted in Acquaviva (1997) for Italian (and attributed to Manzotti and Rigamonti 1991), but it has not been discussed much in the relevant literature.

$$
\begin{aligned}
& \text { ??Nessuno studente ha letto nessun libro. } \\
& \mathrm{n} \text { - } \quad \text { student has read n- book }
\end{aligned}
$$

(Acquaviva 1997: 69)

The sentence above is reported impossible on the intented NC reading. Similarly, structures with two n-words functioning both as determiners are excluded in Spanish and Catalan (Josep Quer, personal communication). Compare the two sets of sentences below:
a. Ningún estudiante
dijo
b. Cap estudiant
(no) va dir
n- student
not said
'No student said anything.'

nada.

Spanish

res.

Catalan
a. ??Ningún estudiante contestó
n- $\quad$ student answered.3sg
b. ??Cap estudiant va contestar
n- student aux.3sg answer

$$
\begin{aligned}
& \text { ninguna pregunta } \\
& \text { n- question } \\
& \text { cap pregunta } \\
& \text { n- question }
\end{aligned}
$$

Spanish

Catalan

According to the native speaker's intuition, the unacceptable judgment in Spanish is due to the fact that it points to a double negative reading which is, however, not possible. In Catalan, on the other hand, if we add SN 'non' the result is a NC reading 'No student answered any question' and not the double negative reading 'it is not the case that no students answered any questions'. This is so because addition of SN in Catalan does not yield double negation, as we just saw (60).

We surely want to link these facts to other distinctive feature of Romance NC regarding the position of n-words (preverbal or postverbal) that we tackle immediately below. Most importantly, if the relevant n-words were inherently negative, we wouldn't expect to see the contrasts presented here; double negative and $\mathrm{NC}$ readings should be freely allowed (depending on whether we apply the rule of negative absorption or not), contrary to fact. On the other hand, the different judgements we get between bare n-words and determiner n-words could be made to follow if we assumed that bare n-words are negative quantifiers, but determiner words are indefinites: the non-co-occurrence of two determiner n-words would then follow as a nonlicensing, since there is no negation. Two bare n-words, on the other hand, would form a 
branching negative quantifier structure yielding one negative reading. In fact, the reinterpretation of negative absorption as branching quantification seems to be a desirable move for explaining the pattern of negative spread (as suggested in Giannakidou 1997: 151; see Sag and de Swart 2002 for an implementation of this idea as resumptive quantification in French).

Going back to the comparison between strict and non-strict NC varieties, we should note again that Greek, Hungarian, and the Slavic languages do not exhibit negative spread and require $\mathrm{SN}$, regardless of the number of n-words. In the example below (from Giannakidou 2000) we see that the number of $n$-words that can occur in a sentence is unlimited, and the presence of SN is still obligatory:

$$
\begin{aligned}
& \text { KANENAS *(dhen) ipe POTE TIPOTA se KANENAN. Greek } \\
& \text { n-person not said.3sg n-ever n-thing to n-person } \\
& \text { 'Nobody ever said anything to anybody.' }
\end{aligned}
$$

Given this clear empirical contrast between Romance languages and strict NC languages regarding the obligatoriness of the $\mathrm{SN}$, it seems reasonable to expect that the semantic properties of n-words in these two core varieties will not be the same. The existence of negative spread, as well as the fact that double negation readings arise with bare n-words and negation indicates that these particular n-words may indeed contribute negation, as we just suggested; but in strict $\mathrm{NC}$ varieties n-words obviously do not convey logical negation, since they always need $\mathrm{SN}$, and license only NC readings. ${ }^{7}$

Not all Romance languages, however, allow negative spread; recall example (60) above from Catalan, which allows the SN with more than one n-words. Romanian forms an even stronger exception: it requires strict $\mathrm{NC}$, and does not allow negative spread at all (data from Bernini and Ramat 1996: 176, 186)

$$
\begin{array}{ll}
\text { a. } & \text { Nimeni *(nu) vine. } \\
& \text { n-person not come.3sg } \\
& \text { Noone is coming.' } \\
\text { b. Nimeni *(nu) vazu nimic. } & \text { n-person not saw.3sg n-thing } \\
\text { 'Nobody saw anything.' }
\end{array}
$$

Obviously, then, the semantic content of n-words in Romance is not uniform. Instead we seem to have a scale which includes on the one end Romanian, which is strict NC, and on the other end Spanish, Italian and Portuguese which allow for negative spread. Catalan is in between the two ends. This situation clearly suggests that the semantic content of Romance n-words vis-àvis negativity must be different in each variety.

Before closing this section it is worth reminding that, as noted in footnote 1 , negative spread patterns are marginally found in languages that typically do not exemplify NC, e.g. Dutch and German. These cases, however, are restricted to certain contexts, and exhibit special emphatic intonation which marks their exceptional use.
Hier hilft KEINER
KEINEM.
German
here help.3sg n-person
'Noone helps anyone here. '
n-person

Negative quantifiers can, then, occasionally form branching structures, independent of NC. It seems that almost none of the NC languages that have been thoroughly studied in the literature makes exclusive use of negative spread. French may be an exception to this generalization, as we shall see in 3.3 .

\subsection{The position of n-words: preverbal versus postverbal}


A distinctive feature of non-strict NC varieties of Romance is that the presence of the SN may be disallowed even in structures with one n-word. This happens when the n-word is preverbal, as we see in the examples below from Spanish and Italian (Zanuttini 1991). Generally, then, while preverbal n-words exclude SN, postverbal ones require it. This fact is further illustrated below with data from Spanish:
a. $\quad$ Mario *(non) ha visto nessuno. Mario not has seen n-person 'Mario didn't see anybody.'
b. Nessuno (*non) ha visto Mario. n-person not has seen Mario 'Nobody saw Mario.'

(Italian; Zanuttini 1991)

a.
a. $\quad$ Pedro *(no) ha visto a nadie.
Peter not has seen n-person
'Peter didn't see anybody.'
b. Nadie (*no) ha visto a Pedro. n-person not has seen Pedro 'Nobody saw Pedro.'

Spanish

The b-sentences with preverbal n-words have the expected single negation $\mathrm{NC}$ reading only if $\mathrm{SN}$ is absent. The reading is illustrated below for the Spanish sentence; the universal negation is employed for uniformity, but as we said, the existential version is equivalent:

$$
\forall \mathrm{x}[\operatorname{person}(\mathrm{x}) \rightarrow \neg \text { saw }(\mathrm{x}, \text { Pedro) }]
$$

If we do insert $\mathrm{SN}$, we get the double negation reading:
a. Nadie no ha visto a Pedro. n-person not has seen Pedro 'Nobody saw Pedro.'
b. $\quad \neg(\forall \mathrm{x}[$ person $(\mathrm{x}) \rightarrow \neg$ saw $(\mathrm{x}$, Pedro $)])$

The asterisk in the b examples in (67) and (68) is intended to show the absence of this double negation reading. Putting the facts together, we have to conclude that in preverbal position the nword itself seems to contribute a negation, so that the addition of SN amounts to the addition of one more negation in the logical structure. The obvious question is: if the NC rule cancels out multiple negations in postverbal positions, why doesn't it apply in the case of preverbal ones? If n-words are negative we should expect double negative readings to arise indiscriminately with preverbal and postverbal positions.

The best we can come up with is to stipulate an additional syntactic condition that negation must be expressed at the topmost level of the sentence, and that this can be done either by SN itself, or by an n-word (which is essentially the proposal in Zanuttini 1991). Once the nword is inserted, the condition is satisfied, and the insertion of SN would add another logical negation; the condition would not affect the postverbal postion, obviously. Crucially, the condition would affect not only a preverbal subject, but also a topicalized preverbal n-word. Note also that the condition concerns exclusively the combination of a preverbal n-word and $\mathrm{SN}$ : we don't have double negative readings with a preverbal and a postverbal n-word in negative spread. Apparently, this is so because with two bare n-words a different operation applies - the formation of negative branching - hence the negation-topmost condition does not apply. At any rate, to the extent we need the negation-topmost condition - and we do seem to need it - we accept that the n-words that the condition applies to convey, in certain positions, logical negation.

In strict NC, e.g. Greek and Slavic, we do not observe preverbal versus postverbal 
contrast; the SN is obligatorily regardless of the position of the $n$-word (see Progovac 1994, Giannakidou 1998, 2000 and works cited there). ${ }^{8}$
a. $\quad$ Mario *(ne) vidi ni(t)koga. Mario not see.3sg n-person
'Mario cannot see anyone.'
b. $\quad \mathrm{Ni}(\mathrm{t}) k \mathrm{ko}$ (ne) vidi Mario.
n-person not see.3sg Mario
'Nobody can see Mario.'
a. O Petros *(dhen) idhe KANENAN. the Peter not saw.3sg n-person 'Peter did not see anyone.'
b. KANENAS *(dhen) idhe ton Petro. n-person not saw.3sg Peter
'Nobody can see Peter.'

\author{
(Progovac 1994: 37)
}

(Progovac 1994: 37)

Greek

(Progovac 1994: 37)

Crucially, both patterns are attested in Catalan, as a preverbal n-word optionally allows the NM whereas a postverbal one requires it (see Quer 1993). Compare the sentence below to the ones above from Spanish and Italian:
a. Ningú (no) ha vist en Pere.
Catalan
n-person not has seen Pedro
'Nobody saw Pedro.'
b. En Pere no ha vist ningú.
Peter not has seen n-person
'Peter didn't see anybody.'

The sentence (a) has the NC reading in (69) and not the double negative one in (70); compare to Hungarian in fn. 9. This fact correlates with the restricted negative spread observed in Catalan that we noted previously in 3.2. The correlation is supported further by Romanian, which does not tolerate negative spread and behaves just like strict $\mathrm{NC}$ varieties in requiring the presence of SN even with preverbal n-words, as we saw in (65). So, again, we are forced to conclude that it is impossible to invoke a uniform characterization for n-words in Romance, certainly not in terms of negativity. The implication of this is that we can't invoke a uniform rule for NC in this language family either.

\subsection{A typology of n-words}

Having illustrated the basic patterns of negative concord, we summarize the results in this section in a typology of n-words. Before we present the final classification, however, there is a language that deserves special mention, and which we have not discussed so far: French.

French can be seen as a language with exclusive use of negative spread. The reason for this is that, although French n-words personne, rien, etc co-occur with the negative marker ne, this marker arguably does not convey logical negation:
a. *Marie n'a vu Paul.
Intended meaning: Mary didn't see Paul.
b. Marie n'a pas vu Paul.
'Mary didn't see Paul.'

Logical negation is expressed by pas; this explains the quite overwhelming tendency in colloquial French to drop ne altogether. Crucially, pas and n-words cannot co-occur, but two (or more) n-words with $n e$ are fine: 


$$
\begin{aligned}
& \text { * Marie n' a pas rien dit. } \\
& \text { (Mary didn't say anything.) }
\end{aligned}
$$

(76) Personne n'a rien dit.

'Nobody said anything.'

We can conclude then, that patterns with French n-words and ne are patterns of negative spread, which squares with the observation that $n e$ can also be dropped. French appears to be unique in that it employs only negative spread and strictly excludes NC proper.

French n-words have been treated in the literature as negative quantifiers (Corblin 1996, Larrivée 1995 among others), as quantificational elements with the force of zero N (Déprez 1997), as indefinites (Corblin and Tovena 1999) and non-negatives (Rowlett 1998), and as ambiguous (Sag and de Swart 2002). Note that sentences with multiple French n-words are systematically ambiguous between a NC and a double negation reading (see a recent posting in the Linguist list 10.1799 by Misako Kitamoto with statistics on this ambiguity based on a sample of 26 speakers), which support the hypothesis that French n-words must be both negative and non-negative. Since we have proposed that negative spread can be analyzed as involving a branching quantifier structure, it seems plausible to say that, at least in negative spread, French n-words are indeed negative quantifiers. But French n-words can also be used in non-negative sentences, e.g. interrogatives, with existential meaning (as we shall see next in section 4), hence we must also allow for a existential interpretation. In section 5, however, we see that French n-words do not receive non-quantificational interpretations, e.g. they cannot be used as predicate nominals, with negation. This fact is clearly problematic for the indefinite-only analysis, as this analysis predicts French n-words to be fine predicate nominals.

We are now in position to provide a typology of n-words in Romance, Slavic, Greek and Hungarian based on the distinction between strict and non-strict NC and the emprirical characteristics emanating from this distinction. 
Table 1: The distribution of $N$-words in Negative Concord

\begin{tabular}{|l|l|l|l|}
\hline Language & PreVn-word $+S N$ & PostVn-word + SN & Negative Spread \\
\hline 1. Greek & Yes & Yes & No \\
\hline 2. Hungarian & Yes & Yes & No \\
\hline 3. Polish & Yes & Yes & No \\
\hline 4. Russian & Yes & Yes & No \\
\hline 5.Serbian/Croatian & Yes & Yes & No \\
\hline 6. Romanian & Yes & Yes & No \\
\hline 7. Catalan & Yes & Yes & Yes \\
\hline 8. Italian & No & Yes & Yes \\
\hline 9. Spanish & No & Yes & Yes \\
\hline 10. Portuguese & No & Yes & Yes \\
\hline 11. French & No & No & Yes \\
\hline
\end{tabular}

We have a continuum with strict NC on the one end (rows 1-6) and negative-spread-only on the other, identified with French in row 11, which systematically licenses double negative readings. In between we have Catalan, closer to the strict NC end, and Italian, Spanish, and Portuguese, closer to the French end. Keep in mind that the proper set of comparison here is the set of Germanic negative quantifiers which do not allow NC, and therefore answer 'no' to the three possibilities indicated in the table. French is almost identical to the Germanic situation, save for those cases where multiple occurrences of n-words do not allow for double negative readings. We will compare this table to Table 2 in 5.2, where the semantic tests are included; the most important test is, as we will see, the ability to occur in nonnegative contexts with nonnegative readings. We will see that almost all n-words in the non-strict varieties (6-11) can do this; the only exception seems to be Portuguese.

Obviously, n-words in strict $\mathrm{NC}$ cannot be characterized as negative in any sensible way (although they can still provide negative fragment answers; we turn to this immediately). For these languages, then, an approach along the lines of negative absorption must be prima facie excluded.

\section{The issue of negativity}

Let us consider now in more detail the 'negativity' of Romance n-words. Recall first that unambiguously negative quantifiers appear only in languages without NC, e.g. German, Dutch, and English (West Germanic). As we mentioned earlier, the standard diagnostics are two. First, negative quantifiers contribute negative meaning in the absence of SN. Second, when they cooccur, or when they co-occur with a SN, only double negative readings arise. Both facts are illustrated below. 

a. Heeft Frank niemand gezien? have.3sg Frank nobody seen
'Is it true that Frank saw nobody?'
b. Frank heeft niet niemand gezien. Frank have.3sg not nobody seen
'It is not the case that Frank didn't see anybody.' \# Frank didn't see anybody.
c. Niemand zei niets. Iedereen had iets te vertellen. nobody said.3sg nothing everybody had something to say 'It is not the case that nobody said anything. Everybody had something to say.'

In the above sentences niemand and its English counterpart are interpreted as negative quantifiers. The same can be said for niets 'nothing'. I give here the version with $\forall$ without implying that this is the only option; negative quantifier construals can also admit $\neg \exists$ readings (if this is how we chose to interpret n-words as predicate nominals, for example; the issue becomes relevant in 5.2).

$$
\begin{array}{ll}
\text { a. } & {[[\text { niemand }]]=\lambda \mathrm{P} \forall \mathrm{x}[\operatorname{person}(\mathrm{x}) \rightarrow \neg \mathbf{P}(\mathrm{x})]} \\
\text { b. } & {[[\text { nobody }]]=\lambda \mathrm{P} \forall \mathrm{x}[\text { person }(\mathrm{x}) \rightarrow \neg \mathbf{P}(\mathrm{x})]} \\
\text { c. } & {[[\text { niets }]]=\lambda \mathrm{P} \forall \mathrm{x}[\operatorname{thing}(\mathrm{x}) \rightarrow \neg \mathbf{P}(\mathrm{x})]}
\end{array}
$$

So negative quantifiers in West Germanic are inherently negative n-words. Crucially, languages with such n-words do not exhibit NC. Sentences like $(77 \mathrm{~b}, \mathrm{c})$ are unambiguously double negatives. The question now becomes: are Romance n-words, in the non-strict varieties of NC (including Catalan) identical to their counterparts in non-NC languages?

\subsection{Negative meaning and ellipsis}

The most popular alleged piece of evidence for the negativity of n-words comes from the fact that n-words can occur in fragment answers with negative readings (see Zanuttini 1991 for the original observation for Italian). This fact holds for strict as well as non-strict varieties, so we will address it in general terms here:
Q: Who arrived?
a. Nessuno.
'Nobody.'
b. KANENAS.
Italian
Greek

I assume the following definition of what counts as a fragment answer:

(80) Fragment answer

An answer $\alpha$ to a wh-question $Q$ is a fragment answer iff:

(a) $\alpha$ corresponds in form to the wh-XP constituent in Q; and

(b) $\alpha$ is interpreted as a proposition.

It follows from (a) and (b) jointly that a fragment answer is an elliptical structure, since $\alpha$ is a non-sentential constituent which nevertheless receives the interpretation of a sentence. Hence, in the fragment answer above, Nessuno and KANENAS identify who arrived, and, although what appears as an answer in each case is just a NP, the fragment answer they each form is actually interpreted as a proposition meaning Nobody arrived. What has not been sufficiently appreciated in the previous literature is that the fact that $n$-words are interpreted negatively in the 
absence of overt negation does not prove that they are negative. Rather, negation here arises from the fact that we have ellipsis. If we were to spell out full structure, the presence of negation would be indispensable, as indicated below; strikethrough indicates elided material ${ }^{9}$ :

$$
\begin{array}{ll}
\text { A: } & \text { KANENAS [*(dhen)irthe]. } \\
& \text { n-person not arrived.3sg } \\
& \text { Nobody [arrived]. }
\end{array}
$$

There are two similar cases which might indicate that n-words contribute negative meaning in elliptical contexts: (a) coordinations (disjunctions, and possibly also conjunctions), and (b) some apparently equative structures which are interpreted like comparatives, invoking alternatives. We give here Greek examples (from Giannakidou 2000) but similar facts have been documented for Romance (Zanuttini 1991) and Slavic (Przepiórkowski and Kupc 1998):

(82) Thelo na pandrefto ton Petro i KANENAN (alo). want.1sg subj marry.1sg the Peter or n-person (else) 'I want to marry either Peter or nobody (else).'

O Petros ine toso psilos oso KANENAS (alos) stin taksi tu. the Peter is as tall as n-person (else) in-the class his 'Nobody else in Peter's class is as tall as Peter is.' (Implicating that: Peter is taller than anybody else in his class. Not: Peter is as tall as everybody else in his class.)

$$
\begin{array}{lll}
\ldots i & \mathrm{i}[* \text { (hen) } \\
\text { or not want.1sg subj marry.1sg } & \text { KANENAN. }
\end{array}
$$

... or I don't want to marry anybody.

... oso [* (then ine] KANENAS alos stin taksi tu. as not is n-person else in-the class his

Peter is as tall as nobody else in his class.

In these cases, the addition of 'alo' else, which seems necessary for most speakers, signals that we are considering alternatives. Reduced co-ordinations have been argued to be an instance of clausal ellipsis by numerous authors (see Johnson 1996; the same holds for clausal comparatives, for a recent discussion see Lechner 2001).

Further evidence that we are dealing with clausal ellipsis is provided by the fact that in the coordination example (86) the preposition $m e$ 'with' cannot be omitted; this is in agreement with other cases of moved remnants under ellipsis, such as in gapping and sluicing, since Greek does not allow proposition stranding (see Merchant 2001 for the correlation between preposition stranding and the (un)availability of prepositions under ellipsis). On the other hand, DPs can be coordinated in general, as in (87):

Thelo na miliso me ton Petro $\{\mathrm{i} / \mathrm{ke}\}$ want.1sg subj talk.1sg with the Peter \{or/and 'I want to talk to Peter \{or/and $\}$ nobody (else).'

$$
\begin{aligned}
& \text { *(me) KANENAN (alo). } \\
& \text { with n-person (else) }
\end{aligned}
$$

Milisa me ton Petro ke ti Maria. talked.1sg with the Peter and the Mary 'I talked to Peter and Mary.'

Likewise, prepositions cannot be omitted in negative answers:

$$
\begin{array}{ll}
\text { Q: } & \text { Me pjon milises? } \\
& \text { with whom talked.2sg } \\
& \text { 'Who did you talk to?' } \\
\text { A: } & \text { *(Me) KANENAN. }
\end{array}
$$




\section{' (To) Nobody.'}

Again, we see that a language which does not allow preposition stranding, Greek, does not allow omission of the preposition in a negative fragment answer; but in English, a language allowing preposition stranding, the preposition can be omitted with no cost. Hence we have to say that the negative meaning in elliptical fragments arises not as an inherent contribution of the n-word, but rather as the result of their being associated with negation at the level at which ellipsis is resolved.

Watanabe (to appear) questions the ellipsis argument by raising the problem of the antecedent. If the elliptical LF contains negation in a fragment answer, where does this negation come from? The problem is that the antecedent is actually positive; and this goes against the assumption that the ellipsis structure and that of its antecedent must be syntactically isomorphic. Syntactic isomorphism however, is a highly controversial assumption, as shown recently in Merchant (2001), and one that Giannakidou (2000) does not share. Merchant illustrates numerous problems with the arguments for syntactic isomorphism; the problems with LFidentity were also well-known in the purely semantic approaches to ellipsis, and they were even noted in more syntactic approaches like Fiengo and May 1994, where 'vehicle change' was introduced to explain away some of them.

Merchant 2001 proposes an alternative based on (a particular implementation of) semantic isomorphism: the antecedent proposition must semantically license the elliptical one. Licensing is, roughly, a relation between inferences: the elliptical proposition will be licensed only if it can be inferred by the proposition that serves as its antecedent. Following Kartunnen 1977, where questions denote the set of their true answers, a negative fragment answer is indeed licensed semantically by its antecedent in Merchant's terms: a negative answer is part of the denotation of a question, and thus a possible inference from it. A question like who arrived?, denotes the Q-set we see below. This set contains a negative proposition as a possible answer:

$$
\begin{aligned}
& \text { Domain: }\{\text { Frank, Bill }\} \\
& \text { Q: }\{\text { Frank arrived, Bill arrived, Nobody arrived }\}
\end{aligned}
$$

So we do have an appropriate antecedent for a negative fragment answer; but it is found in the denotation of the question, and need not be part of its syntax. That it is the semantics that we need becomes evident in the fact that a plain declarative sentence, like the one below, does not serve as an appropriate antecedent for this kind of ellipsis:

$$
\begin{array}{ll}
\text { A: } & \text { O Janis irthe. } \\
& \text { 'John arrived. ' } \\
\text { B: } & \text { \# Oxi, KANENAS. } \\
& \text { 'No, nobody did.' }
\end{array}
$$

The denotation of an extensional declarative sentence is just a single proposition; if it happens to be positive, as above, it cannot license semantically an ellipsis which needs a negative antecedent.

It thus seems safe to conclude that the negative meaning in ellipsis fragments is not evidence for an inherent negative meaning of n-words. It is a little more complicated to trace the negative antecedent in the coordination and the comparative examples which also license the negative ellipsis; but note that these structures involve alternatives (worlds and degrees), and this may provide the basis for a successful search.

Most importantly, items which indeed have inherent negative meaning, like udhis 'nobody' and udhen 'nothing', are not construed with negation. Udhis, udhen are remnants from ancient Greek with very limited use in the modern language. They are negative quantifiers, and, as we see below, cannot co-occur with negation.

Udhen neoteron $(*$ dhen) exomen.

nothing new not have.1pl

'We don't have any new developments.' 
Sentences like the above belong to a formal register, but when appropriate, they don't allow negation. The absence of NC in ancient Greek is parallel to the absence of NC in English, German and Dutch, and due, apparently, to the fact that a negative quantifier paradigm is employed in these languages. ${ }^{10}$

It appears, therefore, that the ellipsis facts question directly the assumption that $\mathrm{n}$-words are negative quantifiers. True, this conclusion seems safer to make for strict $\mathrm{NC}$ varieties, where the SN is obligatory in every case. But what about non-strict varieties of n-words?

\section{2 Nonnegative readings of n-words}

The decisive fact here is that most Romance n-words can be used in nonnegative contexts without contributing negation. These contexts are typical polarity structures, e.g. interrogative sentences, conditionals, superlatives, and restrictions of universal quantifiers. The fact has been noted numerous times in the literature, and is illustrated below with examples from Catalan, Spanish, and Italian (Quer 1993, Laka 1990 and Acquaviva 1997, respectively):
a. $\quad \mathrm{Li}$ diràs res?
'Will you tell him/her anything?
b. Si aneu enlloc, digueu- m'ho.
if go.2pl anywhere, tell.imp. $2 \mathrm{pl} \mathrm{me}$
'If you go anywhere, let me know.'
c. Tothom qui vulgui res, que m'ho digui. everybody who want.3sg anything, that me tell.3sg
'Everyone who wants something, should let me know.'
a. Perdimos la esperanza de encontrar ninguna salida. lost.1pl the hope to find $n-$ exit 'We lost hope of finding some way out.'
b. Todo aquel que tenga nada que dicir... all who that have.3sg n-thing that say
'Everyone who has anything to say....'
a. 亡̀ venuto nessuno?
have.3sg come n-person 'Has anyone come?'
b. E l'idea piu stupida che abbia mai avuto nessuno. be.3sg the idea more stupid that have.subj.3sg ever had n-person 'It's the dumbest idea I have ever had.

In the above sentences, n-words are unable to contribute negation by themselves. Instead, they are interpreted merely as existential quantifiers, as evidenced by the translations. The comparison with the Germanic (77a), which is a negative question, is quite telling. We have to conclude, therefore, that these Romance n-words, unlike the Germanic ones, are not negative quantifiers. Note that this conclusion holds even for the most relaxed variety of French, which allows both a negative and an existential reading:
Est-ce que tu a vu personne?
'Did you see anybody?' Or,
'Is it true that you saw nobody?'

Hence, Romance n-words are at best ambiguous between a negative and a non-negative, existential meaning. 
In contrast to the rest of Romance, Romanian and Portuguese n-words cannot appear in nonnegative structures at all. This implies that these n-words apparently cannot contribute negative meaning themselves; though this does not seem to be a correct assumption for Portuguese, which, unlike Romanian, allows negative spread and n-words in preverbal position without negation. (We compare the two languages again in the concluding section). Additionally, Romanian and Portuguese n-words seem unable to contribute existential meaning; in this they are in sharp contrast with the rest of Romance languages, which allow existential readings with their n-words to varying degrees. For this purpose an unambiguously existential item is employed:
a. Telefonou $\{*$ ninguém/alguém $\}$ ? (Intended meaning: Did you call anybody?)
b. Se vem $\left\{{ }^{*}\right.$ ninguém/alguém $\}$ estamos perdidos. 'If anybody comes, we are lost. '

Portuguese
a. A telefonat $\left\{{ }^{*}\right.$ nimeni/cineva $\}$ ? (Intended meaning: Did you call anybody?)
b. Dac vine $\{*$ nimeni/cineva $\}$ sîntem pierdu $†$ i. 'If anybody comes we are lost.'

Romanian

(There seems to be no difference between European and Brazilian Portuguese in this respect.). The fact that these n-words are unable to contribute an existential quantifier also casts serious doubt to the hypothesis that they are indefinites. If they were, we would expect an existential reading, contrary to fact.

$\mathrm{N}$-words in strict NC languages exhibit exactly the same pattern: they are not licit in nonnegative contexts. The point is illustrated here with interrogatives:

$\begin{array}{llll}\text { a. } & \text { *Da li Milan voli } & \text { nitkoga? } & \text { Serbian } \\ \text { that Q Milan love.3sg } & \text { n-person } & \text { Russian } \\ \text { b. } & \text { *Nikto } \quad \text { zvonil? } & \text { Hungarian } \\ \text { n-person } & \text { called.3sg } & \text { Greek } \\ \text { c. } & \text { *Olvassot Maria semmit? } & \\ & \text { read.past.3sg Maria n-thing } & \\ \text { d. } & \text { *Idhes } & \text { KANENAN? } & \end{array}$

Greek, Hungarian, and Slavic n-words are ungrammatical without negation. This implies that they are unable to contribute negation on their own, as West Germanic n-words do, despite the fact that their morphological make up seems to have a negative component. As previously, a plausible conclusion must be that $\mathrm{n}$-words in strict $\mathrm{NC}$ are unable to contribute an existential quantifier independently of negation either.

An additional conclusion for $n$-words in strict $\mathrm{NC}$ varieties is that these $n$-words are negative PIs (NPIs), and not just PIs, as those n-words occurring in non-negative contexts arguably are. This claim must obviously be extended to Portuguese, excluding thereby the nword from a nonnegative context as a licensing failure.

The picture we draw here regarding negativity clearly supports the position that we have been arguing for all along, namely that n-words do not form a semantically uniform class across languages. It also seems hard to pin down a class of n-words that are just negative; though Portuguese may be such a case, as we suggest later in the conclusions. Generally, when in nonnegative contexts n-words are either interpreted existentially (Italian, Spanish, Catalan), or they cannot be interpreted at all and are thus ruled out (Romanian, and strict NC). At best, we can only find n-words that are ambiguous between negative and nonnegative readings (French).

Given that n-words may indeed have existential readings, we need to check, finally, what the characteristics of existential readings are, and what their impact is on the analysis of nwords. This is the direction we take next. 


\section{The possibility of having an existential polarity item under negation}

Consider a language like English which employs a negative quantifier and any under negation:

$$
\begin{array}{ll}
\text { a. } & \text { I didn't buy any book(s). } \\
\text { b. } & \neg \exists x[\text { book }(\mathrm{x}) \wedge \text { bought }(\mathrm{I}, \mathrm{x})] \\
\text { a. } & \text { I bought no book. } \\
\text { b. } & \forall \mathrm{x}[\text { book }(\mathrm{x}) \rightarrow \neg \text { bought }(\mathrm{I}, \mathrm{x})]
\end{array}
$$

Existential negation

Universal negation

The two sentences are, of course, truth-conditionally equivalent (though there pragmatic differences; recall our discussion in section 2.3). But crucially, the negative sentence with a PI like any unquestionably involves an existential under negation. ${ }^{11}$ Standard English does not exhibit NC. But imagine that we have a language which is like English in employing an existential item like any under negation, but unlike English, it also has NC. In this language NC must be identified with universal negation, and the n-words used must correspond to a universal quantifier. In Giannakidou 1998, 2000 it is argued that Greek is such a language.

On the other hand, imagine a language that has NC, but unlike Greek and English, does not exhibit a separate existential dependency under negation. If we can show that n-words in that language are not negative, then they must be ambiguous between the universal and existential readings we have identified here. In Giannakidou 2000 it is suggested that (a number of) Slavic n-words must belong to this type; we illustrate the relevant diagnostics in 3.2. Recall from 2.2. that we do not want to treat this as an indefinite ambiguity, as there is no evidence for quantificational variability, and the universal meaning cannot be introduced in this context without violating compositionality. Rather, as genuinely ambiguous, we would expect the Slavic $\mathrm{n}$-words in question to jointly exhibit the properties of universal n-words that we have thoroughly discussed so far, and those of existential items that we will present here.

Whether we call existential items 'n-words' or just PIs seems a harmless terminological choice; the characterization 'PI' nevertheless reflects more accurately the fact that these items are not strictly negative PIs and are licensed routinely in non-negative polarity environments-some existential PIs in more environments than others, any being very broad in this respect. Nwords which receive existential interpretation are also licensed in nonnegative environments with precisely this interpretation, as we saw in 4.1.

The syntax of existential dependencies under negation and NC differ in one important respect: locality. This basic difference manifests itself in three ways, which I illustrate immediately in 5.1. There are also clear semantic differences between existential PIs and nwords under negation, to be presented immediately afterwards in 5.2. The discussion will provide us with a number of diagnostics that will enable clear comparisons between languages, which we summarize in 5.3.

\subsection{Negative concord versus existential dependencies: locality}

In this section, we illustrate that, unlike NC, existential dependencies under negation are not clause-bounded. The argument can be made very clearly for Greek, so I follow here closely the discussion in Giannakidou 2000. Greek has the paradigm of emphatic n-words that we have already been discussing; next to it, Greek employs a homophonous nonemphatic paradigm, illustrated in (101); the English gloss here is intended to capture the semantic affinity to the existential import of any (but nonemphatics do not have free choice readings):

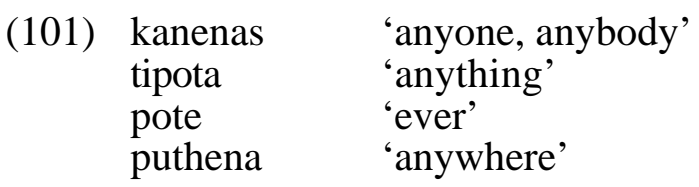


In Giannakidou 1998, 2000 emphatic accent is not focus, but a morphological feature that distinguishes emphatics from nonemphatics. ${ }^{12}$

That nonemphatics are interpreted existentially becomes evident when we consider their interpretation in nonnegative contexts. Nonemphatics occur freely in these contexts, as the equivalents of any; emphatics, on the other hand, never occur in nonnegative contexts:

\begin{tabular}{|c|c|c|}
\hline$(102)$ & Pijes $\quad\{$ pote/*POTE $\}$ sto Parisi? & [interrogative] \\
\hline & $\begin{array}{l}\text { went.2sg n-ever in-the Paris } \\
\text { 'Have you ever (=sometime) been to Paris?' }\end{array}$ & \\
\hline$(103)$ & $\begin{array}{l}\text { An dhis tin Elsa \{puthena/*PUTHENA } \text {, na tis milisis. } \\
\text { if see. } 2 \mathrm{sg} \text { the E. n-where, } \\
\text { 'If you see Elsa anywhere (=some place), talk to her.' }\end{array}$ & [conditional] \\
\hline$(104)$ & I Maria bori na milisi me $\{$ kanenan/*KANENAN $\}$. & [strong intensional verb] \\
\hline & Mary may3sg subj talk with n-person & \\
\hline (105) & $\begin{array}{l}\text { 'Mary may talk to anybody (=somebody)' } \\
\text { Pare }\{\text { kanena/*KANENA }\} \text { milo. }\end{array}$ & [imperative] \\
\hline & $\begin{array}{ll}\text { take.imp. } 2 \mathrm{sg} \text { n- } & \text { apple } \\
\text { 'Take any (=some) apple. ' } & \end{array}$ & [imperative] \\
\hline
\end{tabular}

The inability of emphatic n-words to occur in nonnegative structures shows that they are NPIs, and not just affective polarity items (APIs), as nonemphatics have been characterized in Giannakidou 2000. APIs are interpreted existentially. Romance n-words take over (some of) these API uses that Greek emphatic n-words cannot perform, as we saw, and when they do, Romance n-words are also interpreted existentially.

The licensing of emphatic n-words, as we saw in 2.3, is local in the sense of clausebounded, but the licensing of nonemphatics is unbounded (as first observed in Giannakidou and Quer 1995, 1997). Syntactically, therefore, nonemphatic APIs behave on a par with any and their licensing is quite unconstrained. To appreciate the empirical extent of the freedom of licensing of existential PIs, we present here three representative differences with NC n-words.

\subsubsection{N-words in islands}

Nonemphatics are licensed in syntactic islands. The examples below illustrate this with a relative clause and an adjunct, but more examples are given in Giannakidou 1998. Quer 1993, 1994 reports a similar observation about Catalan n-words, an example of which is given in (108) (from Quer 1993: 30):

Dhen prodhosa mistika [pu eksethesan \{kanenan/*KANENAN $\}$. not betrayed.1sg secrets that exposed.3pl n-person 'I didn't reveal secrets that exposed anybody. '

(107) Dhen milisa [epidhi ithela na prosvalo $\{$ kanenan/*KANENAN $\}]$. not talked.1sg because wanted.2sg subj offend.1sg n-person 'I didn't talk because I wanted to offend anybody (but because I had to).' SCOPE: NOT [Because... anybody]; \# [Because .....anybody] NOT talked

(108) a. No vindra perque vulgui fer res amb ningu. not will-come becaue want.1sg do n-thing with n-person 'I will not come because I want to do anything with anybody.' 
b. No dire secrets que puguin ofendre ningu.

not will-tell secrets that can.pl offend n-person

'I wouldn't reveal secrets that could offend anybody.'

In this respect, nonemphatics and Catalan n-words are like any, which is also fine in islands as we see in the glosses; emphatic n-words, on the other hand, contrast clearly with these and are ungrammatical. The fact that they occur in islands makes it hard to argue that nonemphatics and any are licensed by movement; rather, it seems more reasonable to say that they are licensed in situ as in Giannakidou and Quer (1995, 1997), and Giannakidou (1997, 1998).

The interpretation of nonemphatics and Catalan n-words is identical to any: it is existential, as indicated in the translations. The relevant reading is always with any and the nwords under negation, in agreement with Linebarger 1980, 1987, as indicated in (107). If any and the n-words are outside the scope of negation, they are illicit, a fact noted in Quer 1993. We see this in the sentence below:

(109) *Dhen milisa, epidhi ithela na prosvalo kanenan ke epidhi mu ixan apogorepsi na miliso. *I didn't talk; because I wanted to offend anybody and because they forbade me to talk in the first place.

SCOPE: [because clauses] NOT talked

In this sentence, the because clause is not in the direct scope of negation, as required for these cases (by Linegarger's Immediate Scope Constraint). The problem, of course, is that in this scoping the because-clauses are not negated at all, hence the licensing requirement that PIs be in the scope of its licenser is not met, and the PI becomes ungrammatical.

Again, it is important to note that to the extent that n-word licensing is possible in islands, the n-words that successfully occur there are existentials. Negative quantifiers are of course also allowed as in I didn't talk because I wanted to offend nobody but then they contribute negative meaning. Catalan n-words and Greek nonemphatics do not have this interpretation, and seem to behave just like existentials. Greek emphatics, on the other hand, are unacceptable in islands because they would have to move out of the island in order to scope above negation. It is important to note that n-words in other strict NC varieties exhibit clearly the pattern of Greek emphatic n-words, and not that of nonemphatics or Catalan n-words.

\subsection{2 $\mathrm{N}$-words in embedded clauses}

The basic fact, which correlates with the observations we just made regarding $\mathrm{n}$-words in islands, is that only items with existential meaning can be licensed long-distance. In this, nonemphatic APIs are again parallel to any. We have already seen in section 2.3. the locality constraints imposed on emphatics and the parallelism with quantifier scope. We provide here the relevant contrastive data.

Emphatic items are not accepted in indicative complements of negated matrix verbs. NC is possible only in monoclausal domains and $n a$-clauses. Nonemphatics, on the other hand, and existential/indefinite dependencies with any are fine:

I Ariadhni dhen ipe oti idhe

the Ariadne not said.3sg that saw.3sg

$\{$ tipota/*TIPOTA $\}$.

'Ariadne didn't say that she saw anything.'

I Ariadhni dhen theli na dhi

n-thing

$\{$ kanenan/KANENAN $\}$. 
the Ariadne not want.3sg subj see.3sg

n-person

'Ariadne doesn't want to see anybody.'

The embedding may not be limited to just one complement clause, as illustrated in the sentence below (from Giannakidou 1998); the translation indicates that the same holds for any:
Dhen ipa oti pistevo oti itheles na me katigorisis se
kanenan.
Not said.1sg that believe.1sg that wanted.2sg subj me accuse.2sg to
n-person
'I didn't say that I thought that you wanted to badmouth me to anybody.'

Emphatics are, of course, unacceptable in such cases. The ban on long distance licensing generalizes onto a significant number of n-words in Romance, and strict NC varieties, as illustrated below.

(113) Serbian/Croatian (Progovac 1994: 41)

a. Milan ne tvrdi [da Marija poznaje $\{*$ ni $(\mathrm{t}) \mathrm{koga} / \mathrm{i}(\mathrm{t}) \mathrm{koga}\}$ ].

Milan not claim.3sg that Maria know.3sg n-person

'Milan does not claim that Mary knows anybody.'

b. Ne zelim da vidim $\{$ ni $(\mathrm{t}) \operatorname{kog} a / \mathrm{i}(\mathrm{t}) \operatorname{koga}\}$.

not wish.1sg that see.1sg n-person

'I do not wish to see anybody.'

We see in these sentences that so-called $i$-NPIs (the terminology is from Progovac 1994) in Serbian/Croatian are just like nonemphatics in generally being licensed long distance. Ni-NPIs, on the other hand, are just like emphatics and are licensed only locally. Serbian/Croatian and Greek appear to be identical in this respect: they have two n-word paradigms under negation, of which only one can be licensed long distance; and it happens to be existential. This direct mapping, however, breaks down when we consider clausemate negation. In contrast to Greek, the existential paradigm $i(t) k o g a$ is not licensed with local negation (Progovac 1994: 42):

*Marija ne poznaje i(t)koga.

'Mary doesn't know anybody.'

This fact generalizes over a number of languages in Slavic, and also Hungarian (see the data in Haspelmath 1997, and the works mentioned in this paper on the individual languages). The impossibility of the existential dependency under clausemate negation clearly suggests that $\mathrm{n}$ words must do this job. The anti-locality effect of existentials in these languages was assimilated to the anti-locality we find in pronouns in Progovac 1994; but in the context we assume here it can be seen as a case of blocking: the existential PI is blocked by clausemate negation because the n-word is used to express this meaning. It seem unavoidable, then, to conclude that Slavic n-words do have existential meanings, a conclusion to be supported later on by the fact that they can be used as predicate nominals and that they do not always allow presuppositional readings with negation.

\subsubsection{Preceding negation}


Finally, another typical characteristic of an existential dependency is that the PIs involved in it cannot directly precede negation, as indicated in (115b); nonexistential n-words, on the other hand, can.
a. KANENAN dhen idha. n-person not saw.1sg 'I saw nobody.'
b. *Kanenan dhen idha.
* Anybody I din't see.

The n-word preposing is always optional. Again, we observe the parallel with nonemphatics and any here; the usual assumption for these items is that they must be licensed in the c-command domain of their licenser in order to be grammatical, and that c-command must hold at s-structure (though extensive arguments have also been presented recently that c-command must hold at LF (see Uribe-Etxebarria 1994, Giannakidou 1998; also Hoeksema 2001 for noting the insufficiency of the s-structure conditions.) We need not delve into further details. What matters is that, unlike Greek nonemphatics, n-words in the other languages we are considering, including of course also emphatics, can freely precede negation, hence they are in sharp contrast with existential/indefinite PIs.

To conclude this section, we saw that unlike universal n-word licensing, existential licensing under negation is unbounded, proceeds through islands, and is not subject to sstructure c-command. Hungarian, Slavic, and many Romance languages lacking the existential paradigm under negation, obliterate the distinction overtly attested in Greek. ${ }^{13}$ This explains, for instance, why some of these n-words occur in islands (recall the Catalan n-words), or why they receive existential interpretations in the absence of negation (recall the data in section 4).

Next, we review some additional diagnostics which will help us further decide whether an n-word could be existential or not.

\subsection{Existential polarity items and the semantics of n-words}

In this section, we review some central arguments in support of the observation that the semantic import of PIs like any and nonemphatics is existential. We contrast the semantics of the two paradigms to that of universals on the basis of a number of diagnostics.

\subsubsection{Almost/absolutely modification}

$\forall$-quantifiers, but not indefinites of existentials $(\exists)$, can be modified by almost/absolutely (see Dahl 1970 and Horn 1972 for the original observation). We see below that only emphatics admit almost/absolutely modification.

(116) a. * Electra was willing to accept \{absolutely/almost $\}$ something.

b. Electra was willing to accept $\quad$ absolutely/almost $\}$ everything.

(117) a. Dhen idha sxedhon $\{$ KANENAN / *kanenan $\}$.

not saw.1sg almost n-person

'I saw almost nobody.'

b. Dhen idha (apolitos) $\quad$ KANENAN / *kanenan $\}$ (apolitos).

not saw.1sg absolutely n-person absolutely

'I saw absolutely nobody.'

$\mathrm{N}$-words in the various Romance languages also admit almost/absolutely under negation. But, 
as shown in Quer 1993, 1994, almost /absolutely modification fails in nonnegative contexts, where the n-words are interpreted existentially (recall the data in section 4.2). This contrast supports the view we are pursuing that Romance n-words in the non-strict varieties are ambiguous between existential and possibly negative readings (given that they allow negative spread and can be interpreted negatively in the preverbal position), and are illustrated below:
a. Non ho visto quasi nessuno.
'I saw almost nobody.'
b. *Ha visto quasi nessuno?
*Did he see almost anybody?
Italian

(119) a. No he dit absolutament res.
'He said absolutely nothing.'
b. * Li diras absolutament res?
* Will you tell him/her absolutely anything?
c. *Si aneu absolutament enlloc, digeu-m'ho.
if go.2pl absolutely n-where tell.imp.it
'If you go absolutely nowhere, tell me.'

More examples are given in Quer 1993, 1994 further supporting the contrast between existential and nonexistential interpretations and the possibility or not to admit almost/absolutely as modifiers. It has been a popular strategy in the recent literature question the results of the almost test (e.g. Horn and Lee 1995, Déprez 1997), but see Giannakidou 2000: $472: 474$ for extensive discussion of why the potential counterarguments do not threaten the generalizations we observe here.

\subsection{2 ke-'and' modification}

The second difference concerns $k e$-modification. $K e$ 'and' is a modifier of existential quantifiers, and emphatics are incompatible with it. This expression is comparable to Dutch ook maar, German auch nur. In (120) we see that ke and its ilk are incompatible with universals:
a. Dhen ipe ke \{kati/ *katheti\} spudheo.
not said.3sg and something /everything important
'He didn't say something important.'
b. Dhen ipe ke $\{$ tipota / *TIPOTA $\}$ spudheo.
not said.3sg and n-thing important
'He didn't see anything important.'
c. Wil jij \{ook maar iemand/ *iedereen $\}$ zien?
want.2sg too prt somebody/ everybody see
'Do you want to see anybody?'

Emphatics, then, behave on a par with universal quantifiers as far as ke-modification is concerned. Nonemphatics, on the other hand, are well-behaved existentials. The test can be checked with the other languages under consideration (see Suranyi 2002 for application to Hungarian).

\subsubsection{Donkey anaphora}

Like universal quantifiers and quantificational elements in general, universal n-words do not license donkey anaphora, a point extensively discussed in Giannakidou (1997, 1998):

(121) I fitites pu exun $\left\{\mathrm{kati}_{1} /\right.$ tipota $\left._{1}\right\}$ na pun, as to pun tora. 
the students that have.3pl something/n-thing subj say.3pl, let it say.3pl now 'The students that have \{ something ${ }_{1} /$ anything $_{1}$ \} to say should say it ${ }_{1}$ now.'

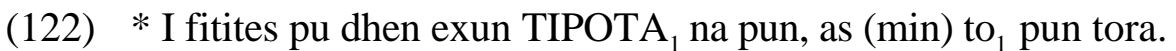
(* The students that have nothing ${ }_{1}$ to say, let them (not) say it ${ }_{1}$ now).

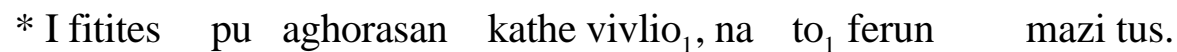
the students that bought.3pl every book, subj it bring.3pl with them

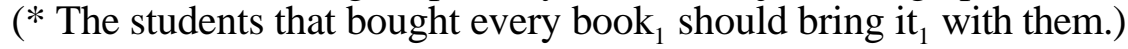

In these examples we see that nonemphatics behave dynamically: they can establish anaphoric links from a relative clause just like existential quantifiers. Any behaves no different in this respect. Emphatics and universal quantifiers, on the other hand, are static: they cannot bind variables outside their scope, as we see in (122) and

(123), respectively.

Richter and Sailer 1998 note that Polish n-words behave on a par with emphatics with respect to donkey anaphora, a fact suggesting that they receive universal interpretation. But they express reservations for the validity of the test, by saying that negation creates islands for anaphora anyway (see also Suranyi 2002); for instance:

(124) * The students that didn't buy $\{$ any/some $\}$ book should show it now.

In this declarative sentence, negation binds off the variables contributed by any book and some book and anaphora is blocked, since there are no discourse referents to be picked by the pronoun in the main clause. However, there are declaratives which actually allow anaphora even through negation; an example is given below, attributed to Barbara Partee:

(125) This place doesn't have a bathroom, or it has it in a strange place.

Hence it is not entirely true that anaphora is blocked under negation. Even more frequently, existentials can bind pronouns under negation in directive sentences, as the examples below illustrate with nonemphatics; any appears to have a limited ability to do the same:

Don't check any book ${ }_{1}$ out from that (Satanic) library; reading it $_{1}$ might warp your mind.

b. Min agorasis kanena vivlio ${ }_{1}$; bori na apodixti pro $_{1}$ epikindino. not buy.2sg n- book may subj prove.3sg dangerous 'Don't buy any book ${ }_{1}$; it $_{1}$ might prove dangerous.'

In the negated imperative-like (126a), anaphora is enabled across negation and might between any book and $i t$, and the same can be said for (126b) (though in this sentence the bound reading may be not the most salient reading in English). Imagine the context of a dictatorial regime, where some books are fobidden by the government, and whoever buys them runs the risk of going to jail. In this context, (126b) can be felicitously uttered, meaning either "buying books will prove dangerous", or "the books that you buy may be dangerous". The second reading is the one indicated in the indexing in (126b). Emphatics, crucially, do not allow this reading; universal quantifiers don't allow it either:

(127) Min agorasis KANENA vivlio ${ }_{1}$; bori na apodixti $\quad$ pro $_{*_{1}}$ epikindino. not buy.2sg n- book may subj prove.3sg dangerous 'Buy no books; it might be dangerous (if you buy). '

(128) Min agorasis kathe vivlio ${ }_{1}$; bori na apodixti pro $_{*_{1}}$ epikindino. not buy.2sg every book may subj prove. $3 \mathrm{sg}$ dangerous 'Don't buy every book; it might be dangerous (if you buy them all).' 
(127) has only the reading where buying books can prove dangerous, and likewise, (128) can only mean "buying all the books will be dangerous". Hence directive negative sentences are indeed static for universal quantifiers and emphatics, but still dynamic for nonemphatics and any. Why anaphoric links with negation are more easily established in directive sentences is a more general issue that needs to be addressed in the context of donkey anaphora, but not of direct relevance here.

Though the discussion above has certainly not exhausted the subtleties and variation arising with donkey anaphora, the clear contrasts we witnessed in this subsection allow us to pair emphatics with universal quantifiers, and nonemphatics with existential quantifiers. Most significantly, n-words in other strict NC languages, e.g. Hungarian, Polish, Serbian, and possibly other Slavic languages, and Romanian behave on a par with emphatics (Richter and Sailer 1998, Blaszczak 1999). Below, we give examples supporting this point from Hungarian and Romanian.

(129) *A diakok akiknek van (sem) semmi (sem) mondanivalojuk most kene mondjak.

* The students that have (not) n-word (not) to say should say it now.

(130) *Studentii care nu au nimic de spus ar trebui s-o spuna acum Romanian

* The students that not have n-word to say should say it now.

Obviously, in these languages too, n-words are quantificational, hence they cannot bind pronouns outside their syntactic scope.

In some non-strict NC Romance languages, on the other hand, n-words behave like existentials/indefinites, can be licensed in conditionals even without negation, and can bind donkey pronouns. We illustrate below with Catalan; but Portuguese, as we see, is different:
a. Si truca ningú, digues-li que no hi sóc.
Catalan
'If anyone calls, tell him I'm not in.'
b. *Todo aluno que trouxe nenhum livro mostrou-o para mim. (Every student who bought n- book, showed it to me.)
Portuguese

Italian, Spanish, etc. should be just like Catalan, since these languages too allow for existential interpretations of their n-words. We note again that Portuguese n-words form the exception which, as we saw in 5.1, do not receive existential interpretations at all, are not licensed in nonnegative contexts, thus also not in the restriction of a universal quantifier.

\subsubsection{Use in predicate nominals}

Existential PIs can occasionally be used as predicate nominals under negation; but nonexistential n-words cannot. The contrast is visible again in Greek: on a par with universals and unlike nonemphatics and regular existentials, emphatics cannot be used as predicate nominals, as shown in the examples below; this fact was first observed Quer 1993 and Giannakidou and Quer 1995:

$$
\begin{array}{lll}
\text { (132) } \begin{array}{l}
\text { Dhen ine }\{\text { kanenas } / * \text { KANENAS }\} \\
\text { Not be.3sg n- }
\end{array} & \begin{array}{l}
\text { jatros. } \\
\text { doctor }
\end{array} \\
\text { 'He is no doctor.' } & \\
\text { (133) } & \text { Frank is }\{a / * \text { every }\} \text { student. }
\end{array}
$$

Partee 1987 discusses restrictions on the availability of type-shifting to predicative (type $<e, t>$ ) interpretations. She argues that type lowering from $\langle\langle e, t\rangle, t\rangle$ to $\langle e, t\rangle$ is not allowed for universals: they must always be assigned the generalized quantifier type $(\langle\langle e, t\rangle, t\rangle)--$ the reasons why this is so are immaterial here. The unacceptability of emphatics in predicate 
nominal positions indicates that emphatics cannot be lowered to the predicative type. Nonemphatics, on the other hand, make perfectly good predicate nominals.

Admittedly, the sentence (132a) differs from the corresponding one with the bare NP below, which is the unmarked option:

(134) Dhen ine jatros.

not is doctor

'He is not a doctor.'

The difference in Greek between the two options is exactly parallel to the one we observe with the corresponding sentences in English: the no doctor version is marked, and has a pejorative flavor in it. In the case of $\mathrm{He}$ is no doctor the person in question can still be a doctor, but just not a good one. He is not a doctor, on the other hand, states that the person in question does not have the property of being a doctor, and it is true only in this situation.

What is the situation with other n-words? The crosslinguistic picture seems split. On the one hand, we have n-words that can be used as predicate nominals; on the other, we have nwords that follow the Greek pattern and cannot be used for this function. French, Italian, Hungarian (see Suranyi 2002), and Romanian illustrate the latter, thus confirming the quantificational pattern:
a. $\quad$ Non è nessun dottore.
Italian
b. $\quad$ * Il n' est aucun docteur.
French
He not is n- doctor
c. *Maria nu e nici un doctor.
Maria not is n-word a doctor
Romanian

(136)

* Mari se orvos.

'Mari no doctor.'

Hungarian

Hence the Greek, Hungarian, and Romanian varieties of strict NC form a natural class in this respect. The Slavic variety, however, gives a different picture. Polish, Russian, and Serbian nwords can indeed be used as predicate nominals (Richter and Sailer 1998, Blaszczak 1999).
a. On nie jest zadnym lekarzem.
he not is n- doctor
He is no doctor.
b. Nikakoj on ne vrach.
n- he not doctor
c. Jovan nije nikakav doctor.
Polish
Russian
Serbian

So there is a clear division with strict NC regarding the option of n-word predicate nominals, and the use of $n$-words is always a marked option, accompanied by a pejorative meaning.

Catalan is in between: in most cases it excludes n-words from predicate nominal positions, but occasionally it allows them to appear there, if they are construed with abstract nouns and convey the evaluative meaning we have observed:
(138) a
No és cap geni.
Catalan
not is no genious
'He's no genious.'
b No és cap meravella.
not is no marvel
'He's no wonder.'
c No és (*ap) metge. 
not is no doctor

Apparently in Catalan the noun 'doctor' is not amenable to a pejorative interpretation, thus the ungrammaticality of c. At any rate, the pattern confirms the observation that if a language allows for existential readings of n-words, as Catalan does systematically, then it will allow them to occur in predicate nominal positions.

In the same spirit, the Russian, Polish, and Serbian data seem to suggest that n-words in these languages are amenable to existential interpretations, at least in these cases. This conclusion would be consistent with the observation that we made earlier vis-à-vis the fact that these languages do not employ another existential PI-paradigm under negation. The question then is: if Slavic n-words can be existential, why doesn't their existential import surface in other contexts, e.g. with interrogatives and other nonnegative contexts, as in the case of Catalan nwords, for example? The only way to handle this question is to postulate, as we did earlier, that $\mathrm{n}$-words in Slavic are NPIs and therefore licensed only by negation; we can content ourselves with such an answer at this stage - although, surely, as with every polarity phenomenon, we would like to know what the deeper lexical semantic source of this fact is.

Going back to Romance n-words that do not tolerate predicate nominal uses and comparing these to Catalan, an interesting correlation emerges: the Romance languages that disallow predicate nominal n-words are more limited than Catalan in licensing their $\mathrm{n}$-words in nonnegative contexts with existential readings; Catalan seems to be the most liberal case given the documented facts (Quer 1993, 1994). Since Portuguese does not license existential meanings with n-words, as we saw, we would expect it to block predicate nominal uses altogether; but this is not what we get:

(139) O Pedro não é nenhum médico.

The Pedro not is no doctor

'Pedro is no doctor.'

If Portuguese n-words are negative, as we have accepted in 4.2, this data suggests that nenhum medico is just like the English no doctor. Note that Portuguese also exhibits the unmarked pattern of negation and a (bare) infinitive that is generally available in the languages we are discussing. including English. Crucially, the very fact that negative quantifiers are used in this marked pattern as predicate nominals casts doubt on the general applicability of this test. We will discuss some more data below, and continue assuming that the possibility of a predicate nominal use may indicate existential meaning, but we should keep in mind that the predicate nominal test may actually not be one of the most reliable diagnostics.

A question arises regarding Italian and French (and also Spanish) which do seem to allow existential uses, albeit more restricted than Catalan. Why can't the existential reading arise under negation? An answer that suggests itself is the following. If we assume, as we do in this paper, that French, Italian and Spanish n-words are ambiguous between negative and existential quantifiers, and if the negative quantifier meaning is the meaning that appears with preverbal nwords, then, under negation postverbally these Romance n-words would be existentials, hence they could type-shift to a predicative type. We must assume, quite tentatively, that what blocks this shift is the fact that the unmarked option with an indefinite exists in these languages. (In Greek, presumably, the shift is not blocked because there are two series of n-words.).

Now, if Romance n-words in postverbal position are not negative quantifiers, we can explain why they are bad without negation, unlike Germanic n-words:
a. * Gianni è
nessun dottore.
Italian
John is
n- doctor
b. * O Pedro
é nenhum médico
Portuguese
c. Hij is geen aarts.
Dutch
d. He is no doctor.
e. Er ist kein Artzt.
German 
Romance n-words are additionally polarity sensitive: they need negation to be licensed in the postverbal position. Hence sentences like (140) are ruled out as licensing failures.

In German and Dutch, finally, negative quantifiers are the only means to express the [neg+indefinite] meaning, whereas in English there is the less evaluative option of He is not a doctor; hence the nonequivalence of no doctor to not a doctor that we noted. Crucially, the use of inherently negative n-words as predicate nominals may be an argument in favor of a decompositional analysis of negative quantifiers as $\neg \exists$ (as has actually been proposed for German and Dutch n-words in Jacobs 1991, von Stechow 1993, and Rullmann 1995), only for languages that do not have the option of an indefinite and negation. Dutch/German and English/Portuguese contrast clearly in this respect, as we saw.

\subsection{Summary}

Let us conclude the discussion in this section by summarizing the characteristics of existential PIs under negation that we have observed. We give the full list below, incorporating some of the contrasting observations with universal quantifiers we noted in section 2.3.

(141) Diagnostics for existential n-words

An existential n-word has the following properties:

(a) It is licensed freely long distance in complement clauses.

(b) It can be licensed in syntactic islands, e.g. relative clauses and adjunct clauses.

(c) It cannot be modified by modifiers corresponding to almost/absolutely.

(d) It can bind donkey pronouns.

(e) It can be used as a predicate nominal.

(f) It need not express existential commitment, i.e. we can interpret it with an empty restriction.

These properties contrast clearly with those of universal n-words that we repeat here:

(142) Diagnostics for universal n-words

A universal n-word has the following properties:

(a) It is licensed only by local negation; long distance licensing may be allowed only through an infinitival or subjunctive clause.

(b) It expresses existential commitment, i.e. we tend to interpret it with a non-empty restriction.

(c) It can be used as topic in topicalization structures. In these cases it may be coindexed with a clitic pronoun (or a pronoun performing the respective function, if a language does not employ clitic pronouns).

(d) It can be modified by modifiers corresponding to almost/absolutely.

(e) It cannot bind donkey pronouns.

(f) It cannot be used as predicate nominal.

Finally, we note here the properties of negative n-words, in order to have the full set of comparison:

(143) Diagnostics for negative n-words

A negative n-word has the following properties:

(a) It receives negative meaning and excludes sentential negation in the preverbal position.

(b) It receives negative meaning and excludes sentential negation when it co-occurs with 
another n-word (negative spread). The first n-word is usually in the preverbal position (though not always, recall French).

(c) It is licensed only by local negation; long distance licensing may be allowed only through an infinitival or subjunctive clause.

(d) It can be used as topic in topicalization structures. It these cases it may be coindexed with a clitic pronoun (or a pronoun performing the respective function, if a language does not employ clitic pronouns).

(e) It can be modified by modifiers corresponding to almost/absolutely.

(f) It cannot bind donkey pronouns.

(g) It usually cannot be used as predicate nominal.

(We need to qualify (g) with usually, if we want to include Portuguese n-words, which admit predicate nominal uses, in the class of negatives; recall also what we just noted, that the predicate nominal use is not a totally reliable diagnostic.). We see that negative n-words have a number of properties in common with universal n-words, for example (c) through (g), a fact suggesting that it may be more accurate to treat a negative quantifier as having the underlying logical structure of a universal statement. Most Romance n-words exhibit jointly the characteristics of existential and negative n-words. $\mathrm{N}$-words in strict $\mathrm{NC}$ varieties, on the other hand, are either only universals (Greek emphatics), or only existentials (Greek nonemphatics), or they exhibit the properties of both (Slavic n-words). The crucial fact will be the number of n-words a language allows under negation: Greek allows two and therefore splits the two readings, but Slavic languages only have one, and therefore collapse the logical distinction between a universal and an existential quantifier under negation.

We finalize our thoughts in the concluding section below.

\section{Concluding remarks}

Negative concord (NC), as we saw, is not a uniform but a quite diverse phenomenon across languages. The primary goals of this paper were to illustrate the empirical richeness of $\mathrm{NC}$, and familiarize the reader with the various analyses that have been proposed to handle the diversity. Given the interaction between logical negation and quantifiers, we have the following five options as possible interpretative strategies for n-words: (a) n-words can be negative; (b) that nwords can be existential; (c) that n-words can be universal quantifiers; (d) n-words can be ambiguous negative and existential quantifiers; (e) n-words can be ambiguous between universal and existential quantifiers. Apart from the fact that negation with quantifiers involves two logical structures, ambiguity is expected because many languages do not employ a distinct PI with existential meaning under negation; hence n-words inevitably take over some of the existential functions. Crucially, option (b), that n-words are unambiguously existential quantifiers, was not supported by the data discussed here.

We did find convincing evidence, however, that Greek NC instantiates the universal option: n-words in NC are NPI-universals which must scope over negation in order to be properly interpreted. This conclusion was supported by various diagnostics, most prominently: the observed locality in NC, donkey-anaphora, exclusion from predicative use, scope parallelisms between NC and universal quantifiers, the availability of existence inferences under negation with both $\mathrm{NC}$ n-words and universal quantifiers ('presuppositionality'), and the possibility of topicalization. The distinctive feature of Greek NC has been that Greek also employs an existential PI under negation; the n-word, then, is unambiguously universal.

Interestingly, the wealth of facts reviewed here questioned the viability of the negative absorption approach in its pristine form, which posits that all n-words are negative quantifiers. It became clear that there is no evidence that n-words as a general class are unambiguously negative. The only actual piece of evidence indicating inherent negativity is the fact that some nwords can occur preverbally without negation; in this case it is clearly the n-word that contributes negation. But n-words which do that, with the exception of Portuguese, are also admitted in nonnegative polarity contexts, e.g. interrogatives, conditionals, restrictions of 
universals, and in these contexts they contribute not a negative but an existential quantifier. In view of this fact we cannot but conclude that these n-words are at best ambiguous between negative quantifier and existential readings-a conclusion supported also by the semantic tests we applied in section 5.2. This, then, will be our conclusion for Italian, Spanish, French, and Catalan, where in contrast with Greek, no existential PI-paradigm other than the n-word is used; hence the ambiguity is not unexpected. Crucially, the ambiguity correlates with the position of n-words: the negative quantifier meaning arises in the preverbal position with negation; in the postverbal position with negation, and in non-negative polarity contexts, these Romance n-words are existential quantifiers.

Portuguese and Romanian, on the other hand, are different. We saw in section 5 that nwords in these two languages are not licensed in nonnegative contexts. However, Romanian is a strict NC language but Portuguese is strictly non-strict: it freely allows negative spread. If negative spread indicates negative branching, we have to conclude that Portuguese n-words are indeed negative quantifiers; this is, then, a unique case in the sample of languages we have examined. Additionally, we must postulate that in contrast with Germanic negative quantifiers, Portuguese n-words (a) can form branching structures thus giving NC reading with one another, and (b) they are NPIs, hence they must be licensed, and cannot occur in a non-negative context.

Romanian n-words, on the other hand, seem to exhibit the characteristics of universal quantifiers that we discussed illustrating with Greek.

$\mathrm{N}$-words in Slavic languages cannot be negative, as we saw in section 5. Given that Slavic languages employ only one paradigm of n-words under negation, this means that their nwords must be ambiguous between existential and universal meanings. This conclusion is supported by the fact that they scored well on both sides with respect to the number of diagnostics we considered: e.g. Slavic n-words can be possible predicate nominals, but exclude donkey anaphora; they allow pressuppositional readings but they are not forced to have them. Certainly, there are more subtle variations between the individual languages, but it seems relatively safe to assume that the variations will fluctuate within the two options posited here.

Hungarian n-words were argued to be universal quantifiers (Szabolcsi 1981 and subsequent works cited in Suranyi 2002). They behave just like the Greek n-words; but Hungarian does not employ an existential PI under local negation, which opens up the possibility that Hungarian n-words perform this function too. However, their impossibility as predicate nominals and the fact that they do not allow donkey anaphora suggest clearly that they follow the universal pattern. According to Suranyi 2002, Hungarian n-words allow both presuppositional and non-presuppositional readings with negation; if this judgment is correct, then an existential meaning would also have to be an, albeit marginal, option with these n-words.

In this paper, we focused on a limited number of languages and tried to show the intricacies involved in the interpretation of their n-words. The sample has been, of course, too small, considering the many languages that are out there exhibiting some or other form of NC. Though at present we cannot undertake the task of uncovering new varieties of NC, we must be confident that the analyses and diagnostics presented in this paper will prove helpful in the description and understanding of $n$-words in these languages too. The expected meanings and meaning shifts should be drawn from the quite exhaustive repertory we have established in this study.

\section{Acknowledgement}

I wish to thank the editors of the Linguistics Companion for inviting me to write this Case, as well as two reviewers for their helpful comments. The final stages of this research were supported by the Royal Dutch Academy of Sciences (KNAW), whose contribution is hereby gratefully acknowledged. For comments and suggestions, I wish to thank Jason Merchant, Josep Quer and Ljiljana Progovac. I am also thankful to the following people for judgments and discussion of their native languages: Carmen Dobrovie-Sorin and Donka Farkas for Romanian; Josep Quer for Catalan and Spanish; Donka Farkas and Balasz Suranyi for Hungarian; Ljiljana Progovac for Serbian; Maria Aloni, Carlo Ceccheto, and Paola Monachesi for Italian; Cristina 
Schmitt and Joao Costa for Portuguese; and Dave Kaiser for his assistance with the Russian data.

\section{Notes}

${ }^{1}$ Although there is a clear divide between languages that employ NC as a standard structure, and languages that do not, we should note that even languages that don't have NC may allow it occasionally, e.g. Dutch (Giannakidou 1998: 185, van der Wouden 1997: 245), and German (Giannakidou 1998: 185); e.g. Je hebt NOOIT GEEN tijd voor mij 'You never have time for me', from Dutch. These cases are admittedly quite marginal, and have a clear emphatic intonation. With this precaution, statements like "a language has NC" should be taken to mean "a language employs NC as a standard structure". On this point, see also Acquaviva (1993).

${ }^{2}$ A parenthetical note on the status of SN: SN in NC may be 'light', as in the examples in (2), or 'heavy'. Light SNs are usually argued to be heads (see Pollock 1989, and especially Zanuttini 1991, 1997). Romance, Slavic, Greek, and Nonstandard English exemplify NC proper with a light SN. 'Heavy' SNs, on the other hand, are, according to most accounts, XPs analyzed as specifiers of NegP (Pollock 1989, Bayer 1990, Zanuttini 1991, 1997; see also Merchant 2000). Quebecois French, Bavarian, and Afrikaans exhibit NC with a heavy NM, as we see below (see Vinet 1998, Bayer 1990 and den Besten 1986):

$$
\begin{array}{lll}
\text { a J' ai pas vu personne. } & \text { Quebecois } \\
& \text { I have.1sg not seen n-person } & \\
\text { I haven't seen anybody. } & \text { Bavarian } \\
\text { b Ich bin froh, dass ich keine Rede nicht halden brauch. } & \\
\text { I be.1sg glad that I no talk not hold must.1sg } & \\
\text { I'm glad I don't have to give a talk. } & \text { Afrikaans } \\
\text { c Hulle het nooit gesing nie. } & \\
& \text { they have n-ever sung not } &
\end{array}
$$

Mixed cases are also possible. West Flemish forms one such case where light and heavy NMs combine with n-words (for details see Haegeman 1995).

3 In Haegeman (1995) [Spec,NegP] is assumed to be always filled at s-structure, either by a contentive element (an $n$-word) or by a phonologically null expletive NEG-operator. In this context, in West Germanic languages (West Flemish, Dutch, German, Afrikaans) and in Hungarian, the NEG -criterion is met via overt movement of n-words. In Romance (French, Spanish, Italian, Portuguese) and in English operator-CHAINS are invoked (in the spirit of Brody 1995) to ensure satisfaction of the NEG-criterion.

${ }^{4}$ See, however, Giannakidou and Quer 1995, 1997, and Giannakidou 1997 for an analysis of negation as a binary Q-operator with restriction and scope, extending a proposal made in Ladusaw 1994 that negation can be thetic (non-quantificational), or categorical (quantificational). However, the analysis of negation as a binary operator seems hardly motivated, because negation doesn't behave like one. With a Q-binders for instance, a variable appearing in the restriction is still affected by the Q-operator: it is bound by it, which means that it acquires its Q-force:

$$
\begin{aligned}
& \text { a Typhoons usually arise in THIS part of the Pacific. } \\
& \text { b USUALLYx [typhoon (x)] [arise in this past of the Pasific (x)] }
\end{aligned}
$$

The sentence is interpreted as: as for typhoons, they usually arise in this part of the Pacific (and focus actually indicates which material goes to the nuclear scope; more discussion in Krifka et al 1995). The material in the restriction is still in the semantic scope of the Q-adverb and aquires the respective Q-force. With negation, however, there is no way to make the distinction between 
restriction and nuclear scope: if material is allegedly in the restriction of negation, it is no longer affected by it and is interpreted positively, as is if it outside the scope of negation. Thus there seems to be no real motivation to impose a tripartite structure for negation; the results which employed tripartite structures can all be re-analyzed this way.

${ }^{5}$ Taking the opposite track, Progovac (in press) tries to reduce quantifiers in general to negative polarity items, by arguing that all quantifiers, positive or negative, have a polarity feature (positive or negative) which is responsible for their raising. The proposal should be seen as a welcome attempt to give quantifiers morphological features, which would drive their movement in a minimalist analysis. Though the starting point in Progovac's account is the need to morphologically motivate $\mathrm{QR}$, the proposal clearly shares with the quantificational approach to $\mathrm{NC}$ the main idea of reducing the two phenomena, $\mathrm{NC}$ and quantification, to one.

${ }^{6}$ This has an important consequence for the definition of the syntactic domain of PI-licensing: it entails that, despite what we might be inclined to believe, this domain does not always correspond to the c-command domain of the licenser. Though in many cases licensing maps indeed onto a be-in-the-scope-of condition, this mapping is not a conceptual necessity. The type of syntax involved in licensing (or anti-licensing) will be almost exclusively determined by the semantic content of PIs. In the case of NPI- $\forall$, the quantificational semantics and the licensing requirement that NPI- $\forall$ combine with an antiveridical predicate leave no other option but the escape-the-scope-of-condition (for more discussion see Giannakidou 2000).

${ }^{7}$ Despite the fact that they are not negative, n-words in strict NC varieties could still be argued to have a 'negative' feature, as is argued in Brown 1999 and Progovac (in press) for Russian and Serbian. The assumption here is that this feature is uninterpretable on the n-word itself, so the n-word much check it and eliminate it against negation. Even in these terms, however, nwords would be different from negative quantifiers, as these would have to carry an interpretable negative feature (Brown 1999).

${ }^{8}$ Hungarian is an interesting case: it has two series of n-words, what Suranyi 2002 calls a 'bare' n-word, and a second complex one which contains a bare n-word and the morphological SN sem. With a bare n-word we have the standard strict NC pattern; but with the sem-word, addition of SN sem gives ungrammaticality. It is important to note the difference with Romance, where addition of SN does not give ungrammaticality, but yields a double negation reading. For more details, including a syntactic explanation of why the double negation reading is excluded, see Suranyi 2002, and references therein.

${ }^{9}$ As regards fragment answers in particular, consider that bare NP remnants of minimizers can also be used, as leksi 'word' in (i):

(i) Q: What happened? Did he say anything all night?
A: LEKSI!
'Not a word!'

word

It would be quite far-fetched to invoke inherent negative meaning for leksi 'word' here. Rather, the ability of leksi to serve as a felicitous fragment answer with negative meaning arises as a result of the fact that the minimizer is always construed with negation.

${ }^{10}$ Notice that double negative readings are not licensed with udhen. This probably has to do with the fact that these structures are not productive and belong to a very limited register. At any rate, it is worth pointing out the contrast with negative quantifiers in Germanic languages, and the similarity with Hungarian, mentioned earlier in footnote 8.

${ }^{11}$ We need to emphasize this point because any allows the so-called free choice readings too, which may give off the impression of universal qunatification. For extensive discussion of why free choice any is not a universal quantifier see Horn 2000, Giannakidou 2001. Most importantly, however, even if we took any to be a universal, in the case of negation we would still 
have to exclude the scoping of $\forall \neg$, as the sequence *Anybody didn't come is ungrammatical. Therefore, even if we adopt a universal analysis of free choice, under negation we are forced to assume that any can only be an existential (se Linebarger 1980 for more specific details on this).

12 For extensive discussion see Giannakidou 2000. Here, we just note that the accent- asmorphology option is not a 'peculiarity' specific to n-words, but it is observed elsewhere in the grammar of Greek, for instance, to distinguish between 'few"'- LIJI- and 'a few' - liji-, and 'too' $-P O L I$ - and 'very' -poli-.. Using suprasegmental features to perform morphological distinctions is a common strategy across languages-for instance, stress is systematically employed (e.g., pérmit versus permít for the noun versus verb distinction in English), and tone, as in certain African languages.'

13 Note that we are considering here the possibility of a (negative) polarity existential PI, i.e. a PI that will be licensed by negation (and possibly other nonveridical elements) and which will be interpreted inside negation. The languages we are considering employ occassionally indefinite paradigms other than n-words, e.g. free choice items (whose semantics is considerably more complex than that of the simple existential quantifier under negation), or positive polarity existentials equivalent to some. The use of such existentials is not relevant because these are positive polarity items and tend to escape the scope of negation, hence the existential under negation structure would not be correct for them. Greek employs yet another indefinite for this purpose, kapjos. For a comparison between n-words and kapjos see Giannakidou 2000: 480482.

\section{References}

Acquaviva, Paolo: 1993, The Logical Form of Negation. A Study of Operator-Variable Structures in Syntax. Ph.D. Dissertation, Scuola Normale Superiore, Pisa. Appeared also in Garland, 1997.

Acquaviva, Paolo: 1995, Operator Composition and the Licensing of Negative Concord. In Geneva Generative Papers 3/2: 72-104.

Acquaviva, Paolo: 1997, 'Negation and Operator Dependencies', ms., University of Venice.

Aissen, Judith and David Perlmutter: 1983, 'Clause Reduction in Spanish', in David Perlmutter (ed.), Studies in Relational Grammar 1, pp. 360-403, University of Chicago Press, Chicago.

Anagnostopoulou, Elena. 1997. Clitic left dislocation and contrastive left dislocation. In E. Anagnostopoulou, H. van Riemsdijk and F. Zwarts (eds), Materials in Left Dislocation, John Benjamins, Amsterdam and Phila-delphia. 151-193.

Bayer, Josef: 1990, 'What Bavarian Negative Concord Reveals about the Syntactic Structure of German', in Juan Mascaró and Marina Nespor (eds.), Grammar in Progress, pp. 1324, Foris Publications, Dordrecht.

Beghelli, Filippo and Tim Stowell: 1997, 'Distributivity and Negation: the Syntax of each and every', in Anna Szabolcsi (ed.), Ways of Scope Taking, pp. 71-197, Kluwer, Dordrecht.

Besten, Hans den: 1986, 'Double Negation and the Genesis of Afrikaans', in Pieter Muysken and Norval. Smith (ed.), Substrata versus Universals in Creole Languages, pp. 185230, John Benjamins, Amsterdam.

Blaszczak, Joanna: 1999. 'The Riddle of n-words in Polish', ms., Humbolt Universität Berlin.

Bosque, Ignacio: 1980, Sobre la Negación, Catedra, Madrid.

Brown, Sue: 1997, The syntax of Negation in Russian. A Minimalist Approach. CSLI Stanford Publications.

Carlson, Gregory: 1977, Reference to Kinds in English, Ph.D. Dissertation, University of California, Irvine.

Chomsky, Noam: 1995, The Minimalist Program, MIT Press, Cambridge.

Chomsky, Noam. 2000. Derivation by phase. In M. Kenstowitz (ed.) Ken Hale: A life in Language. MIT Press. 
Cinque, G. 1990, Types of A'-dependencies, MIT Press, Cambridge.

Corblin, Francis: 1996, 'Multiple Negation Processing', Theoria LXII, 3, 214-260.

Corbin, Francis and Lucia Tovena. 2001. On multiple expression of negation in Romance. In In D'Hulst et al. (eds) going Romance 1999, Selected Papers. Amsterdam, John Benjamins.

Dahl, Östen: 1970, ‘Some Notes on Indefinites', Language 46, 33-41.

Déprez, Viviane: 1997, 'A Non-unified Analysis of Negative Concord'. In Danielle Forget et al. (eds.), Negation and Polarity: Syntax and Semantics, pp. 53-75, John Benjamins, Amsterdam.

Déprez, Viviane: 2000. Parallel (A)symmetries and the internal structure of negative expressions. Natural Language and Linguistic Theory 18: 253-342.

Farkas, Donka F. and Anastasia Giannakidou: 1996, 'How Clause-bounded is the Scope of Universals?' In Semantics and Linguistic Theory (SALT) VI, pp. 137-155, Cornell University, Ithaca.

Fiengo, B. and Robert May, 1994. Indices and Identity. MIT Press.

Giannakidou, Anastasia: 1997, The Landscape of Polarity Items. Ph.D. Dissertation, University of Groningen.

Giannakidou, Anastasia 1998, Polarity Sensitivity as (Non)Veridical Dependency, John Benjamins, Amsterdam.

Giannakidou, Anastasia: 1999, 'Affective Dependencies', Linguistics and Philosophy 22, 367421.

Giannakidou, Anastasia. 2000. Negative ...Concord? Natural Language and Linguistic Theory 18: 457-523.

Giannakidou, Anastasia. 2001, 'The Meaning of Free Choice', In Linguistics and Philosophy 24;659-735.

Giannakidou, Anastasia and Jason Merchant. 2002. Eliminating Modules in Minimalism. Manuscript. University of Chicago.

Giannakidou, Anastasia and Josep Quer: 1995, 'Two Mechanisms for the Licensing of Negative Indefinites', Formal Linguistics Society of Mid-America (FLSM) 6, pp. 103114. Indiana University Linguistics Club (IULC), Indiana.

Giannakidou, Anastasia and Josep Quer: 1997, 'Long-distance Licensing of Negative Indefinites', In Danielle Forget et al. (eds.), Negation and Polarity: Syntax and Semantics, pp. 95-113, John Benjamins. Amsterdam.

Haegeman, Liliane: 1992, Theory and Description in Generative Grammar: a Case Study in West Flemish, Cambridge University Press.

Haegeman, Liliane: 1995, The Syntax of Negation, Cambridge University Press.

Haegeman, Liliane and Raffaella Zanuttini: 1991, 'Negative Heads and the Neg- criterion', The Linguistic Review 8, 233-251.

Haegeman, Liliane and Raffaella Zanuttini: 1996, 'Negative Concord in West Flemish', in Belleti Adriana and Luigi Rizzi (eds.), Parameters and Functional Heads, Oxford University Press.

Heim, Irene: 1982, The Semantics of Definite and Indefinite NPs. Ph. D. Dissertation, University of Massachusetts, Amherst.

Heim, Irene and Angelika Kratzer: 1998, Semantics in Generative Grammar. Basil Blackwell, Oxford.

Herburger, Elena. 2001. The negative concord puzzle revisited. Natural Language Semantics 9:289-333.

Higginbotham, James and Robert May: 1981, 'Questions, Quantifiers, and Crossing', The Linguistic Review 1, 41-80.

Hoeksema, Jacob: 1997, 'Negative Concord in Middle Dutch', in Danielle Forget et al. (eds.), Negation and Polarity: syntax and semantics, pp. 139-157, John Benjamins, Amsterdam.

Hoeksema, Jacob, 2001. Negative polarity items: triggering, scope and c-command. In Horn, L. and Y. Kato (eds.) Negation and polarity: semantic and syntactic perspectives, Oxford. 62-88.

Horn, Laurence: 1972, On the Semantic Properties of Logical Operators in English. Ph. D Dissertation, University of California Los Angeles.

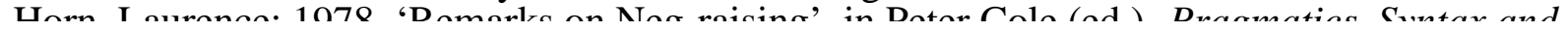


Semantics 9, pp. 129-200, Academic Press, New York.

Horn, Laurence: 1997, 'All John's Children are as Bald as the King of France: existential import and the geometry of opposition', in Chicago Linguistics Society 33, pp. 155-179.

Horn, Laurence: 2000'Any and (-)ever. Free Choice and Free Relatives’. In the Proceedings of the 15th Annual Conference of the Israeli Association for Theoretical Linguistics, ed. by Adam Zachary Wyner. 71-111.

Horn, Laurence and Yung-Suk Lee: 1995, 'Diagnosing the diagnostics', ms., Yale University.

Jacobs, Joachim: 1980, 'Lexical decomposition in Montague Grammar', Linguistics 3, 121136.

Jespersen, Otto: 1917, Negation in English and other languages. Reprinted in Selected Writings of Otto Jespersen (1962), pp. 3-151, George Allen and Unwin Ldt.

Johnson, Kyle. 1996. In search of the English middle field. Manuscript. UMass, Amherst.

Kamp, Hans: 1981, 'A theory of truth and discourse representation', in Jeroen Groenendijk, Theo Janssen, and Martin Stokhof (eds.), Formal Methods in the Study of Language, pp. 277-322, Mathematical Center, Amsterdam.

Kamp, Hans and Uwe Reyle: 1993, From Discourse to Logic, Kluwer, Dordrecht.

Karttunen, Lauri. 1977. "Syntax and semantics of questions". Linguistics and Philosophy 1: 3-44.

Kiparsky, Paul. 1973. Elsewhere in phonology. In Stephen Anderson and Paul Kiparsky (eds.), Feestschrift for Moris Halle. Holt, Rinehart and Winston. New York, pp. 93-106.

Kitamoto, Misako: 1999, 'Negation in French', summary of query 10.1587, Linguist List 10.1799.

Klima, Edward S: 1964, 'Negation in English', in Jerry Fodor and Jerold Katz (eds.), The Structure of Language, pp. 246-323, Englewood Cliffs, Prentice Hall.

Kuroda, S-Y: 1992, Japanese Syntax and Semantics, Reidel, Dordrecht.

Labov, William: 1972, 'Negative Attraction and Negative Concord in English Grammar', Language 48: 773-818.

Ladusaw, William A: 1979, Polarity Sensitivity as Inherent Scope Relations, Ph. D. Dissertation, University of Texas at Austin.

Ladusaw, William A: 1992, 'Expressing negation', in $S$ emantics and Linguistic Theory (SALT) II, pp. 237-259, Cornell University Press, Ithaca.

Ladusaw, William A: 1994, 'Thetic and Categorical, Stage and Individual, Weak and Strong' in Semantics and Linguistic Theory (SALT) IV, pp. 220-229. Cornell University Press, Ithaca.

Laka, Itziar Murgaza: 1990. Negation in Syntax: On the Nature of Functional Categories and Projections. Ph. D. Dissertation. MIT.

Larrivée, Pierre: 1995, 'Quantifieurs Negatifs et Double Negation', in Pierre Larrivée (ed.), Actes des 9e Journees de Linguistique, pp. 207-217.

Lechner, Winfried. 2001. Reduced and Phrasal Comparatives. Natural Language and Linguistic Theory 19:683-745.

Linebarger, Marcia. 1980. The Grammar of Negative Polarity. PhD thesis. MIT.

Linebarger, Marcia: 1987, 'Negative Polarity and Grammatical Representation', Linguistics and Philosophy 10, 325-387.

Longobardi, Giuseppe: 1991, 'In defense of the Correspondence Hypothesis: Island Effects and Parasitic Gap constructions in Logical Form', in James Huang and Robert May (eds.), Logical Structure and Linguistic Structure, Kluwer, Dordrecht.

May, Robert: 1985, Logical Form: its Structure and Derivation, MIT Press, Cambridge.

Merchant, Jason: 2001. The Syntax of Silence: Sluicing, Islands, and the Theory of Ellipsis, Oxford University Press.

Mittwoch, Anita. 2001. Perfective sentences under negation and durative adverbials. In Hoeksema et al. (eds), Perspectives on Negation and Polarity items. John Benjamins. 265-282.

Moritz, Luc and Daniel Valois. 1994. "Pied piping and specifier-head agreement". Linguistic Inquiry 20: 365-424.

Partee, Barbara: 1987, 'Noun Phrase Interpretation and Type-shifting Principles', in Jeroen. Groenendijk et al. (eds.), Studies in Discourse Representation Theory and the Theory of

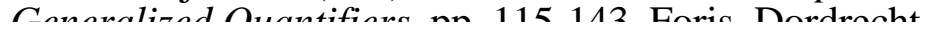


Piñar, Larrubia Pilar: 1996, Negative Polarity Licensing and Negative Concord in the Romance Languages. Ph. D. Dissertation, University of Arizona.

Philippaki-Warburton: 1993, 'The Subjunctive Mood and the Syntactic Status of the Particle na in Modern Greek', Folia Linguistica XXVIII/3-4, 297-326.

Pollock, Jacques Yves: 1989, 'Verb Movement, Universal Grammar and the Structure of IP', Linguistic Inquiry 20, 365-424.

Progovac, Ljiljana: 1988, A binding Approach to Polarity Sensitivity, Ph. D. Dissertation, University of Southern California.

Progovac, Ljiljana: 1994, Positive and Negative polarity: a binding approach. Cambridge University Press.

Progovac, Ljiljana, in press. Negative and positive feature checking and the distribution of polarity items. In Sue Braw and Adam Przepiorkowski (eds.), Issues on Negation in Slavic Languages.

Przepiórkowski, Adam and Anna Kupc: 1997, 'Negative Concord in Polish', Technical Report 828, Institute of Computer Science, Polish Academy of Sciences.

Przepiórkowski, Adam and Anna Kupc: 1998. Eventuality Negation and Negative Concord in Polish and Italian. In Robert D. Borsley and Adam Przepiórkowski (eds.), Slavic in HPSG, CSLI Stanford University. pp. 211-246.

Puskás, Genoveva: 1998, 'On the Neg-criterion in Hungarian', Acta Linguistica Hungarica 45, 167-213.

Quer, Josep: 1993, The Syntactic Licensing of Negative Items, MA thesis, Universitat Autònoma de Barcelona.

Quer, Josep: 1994. Distinguishing between negative and nonnegative licensing of negative items. In the Proceedings of the Colloqium de Grammatica Generativa, Tarragona.

Postma, Gertjan. 1995, Zero Semantics: a Study on the Syntactic Conception of Quantificational Meaning, Ph. D. Dissertation, University of Leiden.

Reinhart, Tanya: 1997, Quantifier Scope: How Labor is Divided between QR and Choice Functions', Linguistics and Philosophy 20, 335-397.

Richter, Frank and Manfred Sailer: 1998, 'LF Constraints on Expressions of Ty2: an HPSG Analysis of Negative Concord in Polish, In Robert D. Borsley and Adam Przepiórkowski (eds.), Slavic in HPSG: 211-246. CSLI Stanford University. pp. 247282.

Rizzi, Luigi: 1990. Types of A'-Dependencies. MIT Press.

Rizzi, Luigi: 1997, 'The Fine Structure of the Left Periphery'. In Liliane Haegeman (ed.), The New Comparative Syntax, Oxford University Press.

Roussou, Anna. 1994. Complementizers in Modern Greek. PhD thesis. University College London.

Rullmann, Hotze: 1995, 'Geen Eenheid', Taalkundige Bulletin 25, 194-197.

Sag, Ivan and Henriette de Swart. 2002. Negation and negative concord in Romance. Linguistics and Philosophy 25: 373-417.

von Stechow, Arnim: 1993, 'Die Aufgaben der Syntax', in von Stechow, Arnim and Dieter Wunderlich, (eds.), Syntax. An international Handbook of Contemporary Research, pp. 1-88, Mouton de Gruyter, Berlin.

Suranyi, Balasz. 2002. N-words in Hungarian. Ms. University of Utrecht.

Swart, Henriëtte de: 1996, 'Scope Ambiguities with Negative Quantifiers', in Klaus von Heusinger and Urs Egli (eds.), Proceedings of the workshop on reference and anaphoric relations, pp.145-164. Universität Konstanz.

Szabolcsi, Anna: 1981: 'The Semantics of Topic/Focus Articulation', in Groenendijk, Jeroen, Theo Janssen, and Martin Stokhof (eds.), Formal Methods in the Study of Language, pp. 513-540, Mathematical Center, Amsterdam.

Szabolcsi, Anna: (ed.): 1997, Ways of Scope Taking, Kluwer, Dordrecht.

Tóth, Ildikó: 1999, 'Negative Polarity Licensing in Hungarian', Acta Linguistica Hungarica 46, 119-142.

Tovena, Lucia: 1996, Issues in Polarity Sensitivity. Ph. D. Dissertation, Universtity of Edinburgh. Also appeared in Garland (1999).

Tsimpli, Ianthi-Maria: 1995, 'Focusing in Modern Greek', in É.Katalin Kiss (ed.), Discourse Configurational Languages, pp. 176-206, Oxford University Press.

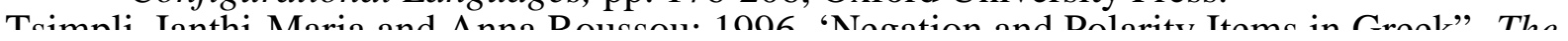


Linguistic Review 13, 49-81.

Uribe-Etxebarria, Miriam. 1994. Interface Licensing Conditions on Negative Polarity Items: a Theory of Polarity and Tense Interactions. PhD thesis, University of Connecticut.

Vallduvi, Enric. 1994. Polarity items, N-words and minimizers in Catalan and Spanish. Probus 6:263-274.

Varlokosta, Spyridoula. 1994. Issues on Modern Greek Sentential Complementation. PhD thesis. University of Maryland.

Veloudis, Jannis: 1982, Negation in Modern Greek. Ph.D. Dissertation, University of Reading.

Vinet, Marie-Thérese: 1998, 'Contrastive Focus, French n-words and Variation'. To appear in Revue Canadienne de Linguistique.

Watanabe, Akira. To appear. Decomposing the Neg-criterion. In D'Hulst et al. (eds) going Romance 1999, Selected Papers. Amsterdam, John Benjamins.

Wouden, Ton, van der and Frans Zwarts: 1993, 'A Semantic Analysis of Negative Concord', in Semantics and Linguistic Theory (SALT) III, pp. 202-219, Cornell University Press, Ithaca.

Wouden, Ton, van der. 1997. Negative Contexts. Routledge, London.

Zanuttini, Raffaella: 1991, Syntactic Properties of Sentential Negation: a comparative study of romance languages, Ph.D. Dissertation, University of Pennsylvania.

Zanuttini, Raffaella: 1997, Negation and Clausal Structure, Oxford University Press, Oxford.

Zwarts, Frans: 1995, 'Nonveridical contexts'. Linguistic Analysis 25, 286-312. 